\title{
Exogenous and endogenous risk factors management to predict surrender behaviours
}

\author{
Xavier Milhaud* \\ Université de Lyon, Université Claude Bernard Lyon 1, Institut de Science \\ Financière et d'Assurances, 50 Avenue Tony Garnier, F-69007 Lyon, France.
}

\begin{abstract}
Insurers have been concerned about surrenders for a long time especially in Saving business, where huge sums are at stake. The emergence of the European directive Solvency II, which promotes the development of internal risk models (among which a complete unit is dedicated to surrender risk management), strengthens the necessity to deeply study and understand this risk. In this paper we investigate the topics of segmenting and modeling surrenders in order to better take into account the main risk factors impacting policyholders' decisions. We find that several complex aspects must be specifically dealt with to predict surrenders, in particular the heterogeneity of behaviour as well as the context faced by the insured. Combining them, we develop a new methodology that seems to provide good results on given business lines, and that moreover can be adapted for other products with little effort.
\end{abstract}

Keywords: risk management, life insurance, surrender risk, mixture models.

\section{Introduction}

How to model the surrender behaviour ? is a frequently asked question in any insurance company. The main reason why the prediction of surrenders still remains a challenge is that we are talking about human decisions, whose complexity may be due to the variety of risk factors (individual characteristics, personal needs, contract features, fiscality constraints, economic context and socio-cultural aspects).

The consequences of surrenders on a life insurer balance sheet can be huge. Indeed when lapsing her contract, the policyholder immediately retrieves its

* Corresponding author. Tel.: +33 (0)1 41176499

Email address: xavier.milhaud.research@gmail.com (Xavier Milhaud). 
surrender value; which is nothing else than the sum of earned premiums, potentially reduced by contractual penalties. Therefore, on the one hand the insurer is faced with a liquidity threat in case of massive surrenders. On the other hand, a high exposure and no surrender on guaranteed return contracts may lead to bankruptcy (except if the company's profitability is higher than these returns, which would never happen in such a context). Both situations may occur following a disturbance of the economy, a damage to the firm's reputation or some regulatory changes: we thus have to integrate these cyclical aspects in the model.

It is essential to keep in mind that structural risk factors should also be considered. Milhaud et al. (2011) suggest to detect the most important variables impacting the surrender behaviour using two complementary segmentation techniques: the CART algorithm (Breiman et al. (1984)), and the logistic regression (Hosmer \& Lemeshow (2000), denoted further by logit). In their study, they show that some contract features as well as policyholder's characteristics play a crucial role in the decision process. Such results could help product designers to adapt their offer so as to to gain market shares for instance. In protection business where the premium size is mainly determined by the policyholder's health, other matters such as adverse selection and moral hazard (Bluhm (1982)) have to be addressed even if this is clearly a hard task. However, insurers partially control these effects and their undesirable consequences thanks to well-known incentives (e.g. deductible or medical examination).

Traditionally, actuaries are used to studying surrenders on two main viewpoints: their financial consequences, and their impact on guarantees. We focus hereafter on the former, which is closely linked to the interest rate dynamics; leaving the latter for further research. To the best of our knowledge, modelling surrenders by mixture models has never been investigated. This enables us to account for the high heterogeneity of human behaviour, which was often the source of difficulties in previous works: Kim (2005) and Kagraoka (2005) used generalized linear models (McCullagh \& Nelder (1989), henceforth referred to as GLM), while others (Bacinello (2005), Siu (2005), Tsai et al. (2002)) developed financial methods to price the surrender option embedded in life insurance policies.

In section 1, we briefly describe the current practice to manage the surrender risk in most of life insurance companies. The second section aims at explaining why a classical GLM approach generally fails to predict surrenders. Section 3 introduces mixture models and our new methodology so as to model surrender behaviours. Finally, an analysis on eight different product families is performed in section 4 to illustrate the effectiveness of the methodology. 


\section{Current practices in life companies}

Most of time the base surrender risk is assessed thanks to descriptive statistics. Indeed, empirical data allow us to calibrate an average surrender rate depending on some characteristics (contract duration, distribution network, ...), and resulting in a multidimensional table (as illustrated on table 1, bidimensional to simplify). The idea is then to adjust the base surrender risk with a "dynamic" function, which is sensitive to market conditions (interest rates and competition) and that must obviously make sense to practitioners.

First, this means that we do not take into account the potential correlation between explanatory variables of the surrender behaviour. Second, the policyholders' decisions have to be mutually independent. Below are the four dynamic functions that are typically used by insurers to stress their best estimate: the two first in $\mathrm{GMxB}^{1}$ business, others in saving business with guaranteed returns.

The simplest dynamic function defines a multiplicative coefficient (figure 1) to be applied to the base surrender risk: this is the step function. This rate is suddenly increased when policyholders are much more likely to surrender their contract, i.e. when the surrender option value does not look satisfying (on a relative scale). On the contrary, the surrender rate goes down as the option gets better.

The linear function adjusts the base surrender rate depending on the surrender option pricing (by financial techniques). As soon as the option gets in the money, the surrender rate linearly goes up (figure 2) for policyholders who are considered sensitive to market conditions.

Sometimes an exponential curve is applied to the base risk depending on the spread, which is defined as the expected return minus the guaranteed rate of the contract. The expected return is either the competitors' best guaranteed rate or a long-term risk free interest rate. To some extent,

- if the spread is negative then exp(slope $\times$ spread $)$ stands for the exponential function, where slope is the (positive) convergence speed to the policyholder's expected return;

1 GMxB: Guaranteed Minimum "x" Benefit. These variable annuities encompass GMDB (Death), GMWB (Withdrawal), GMIB (Income), GMAB (Accumulation).

Table 1

\begin{tabular}{|c|c|c|c|c|c|c|}
\hline Term & Age at underwriting & $\mathrm{L}$ & $\mathrm{L}+1$ & $\mathrm{~L}+2$ & $\mathrm{~L}+3$ & $\mathrm{~L}+4$ \\
\hline 10 & All & $80 \%$ & $29 \%$ & $17 \%$ & $15 \%$ & $15 \%$ \\
\hline 20 & All & $82 \%$ & $27 \%$ & $17 \%$ & $14 \%$ & $14 \%$ \\
\hline 30 & All & $83 \%$ & $29 \%$ & $19 \%$ & $15 \%$ & $15 \%$ \\
\hline
\end{tabular}

Example of surrender assumptions in Term Life. L (e.g. 5 years) is a given contract duration (time elapsed since the issue), " $L+1$ " means one year later and so on. 


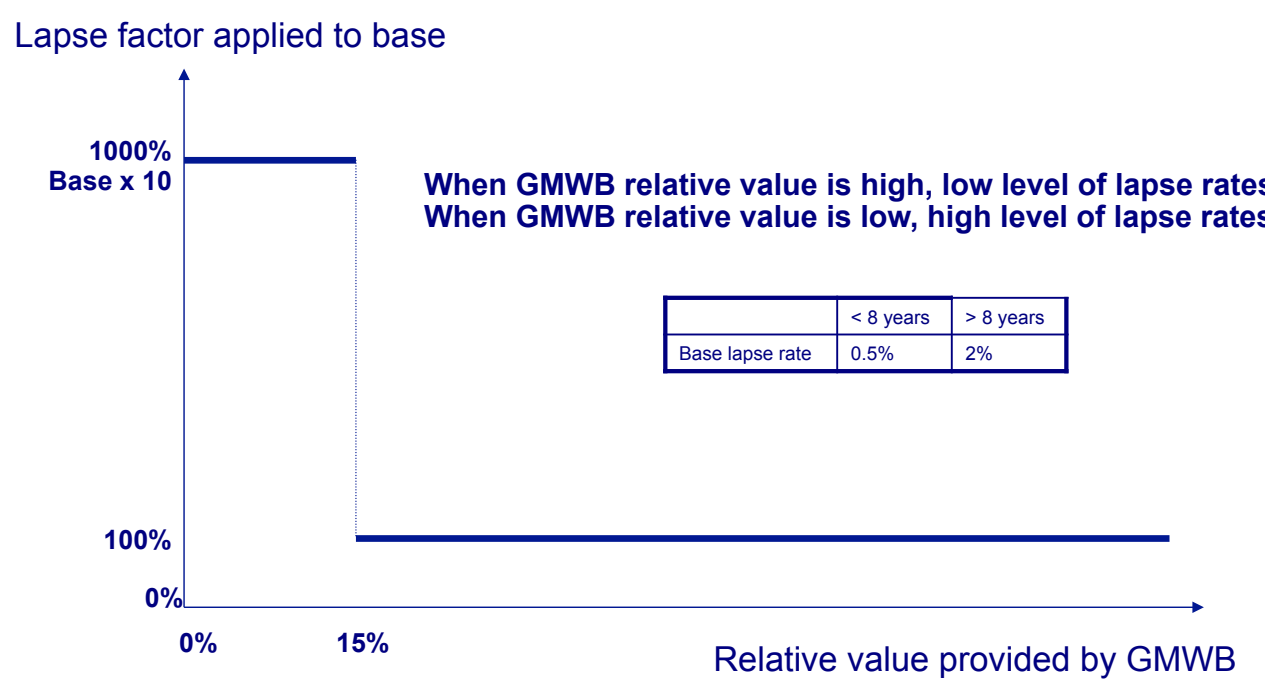

Figure 1. Example of a step function.

- if it is positive (low profitability) then the adjustment is $K-\exp (-\operatorname{slope} \times$ spread), where $K$ is a constant. Basically, the base rate is increased.

Here, the adjustment towards the expected profitability of the contract is slight and continuous.

As compared to other functions, the arctangent function introduces something new: the difference between policyholders' expectations and reality is still based on the spread, but the multiplicative coefficient exponentially increases (figure 3) between two given thresholds. This creates two stable regions and a continuous but sharp transition. It is the most common assumption.

Not surprisingly, the underlying insight is always the same: a satisfied policyholder has a low propensity to surrender, and conversely.

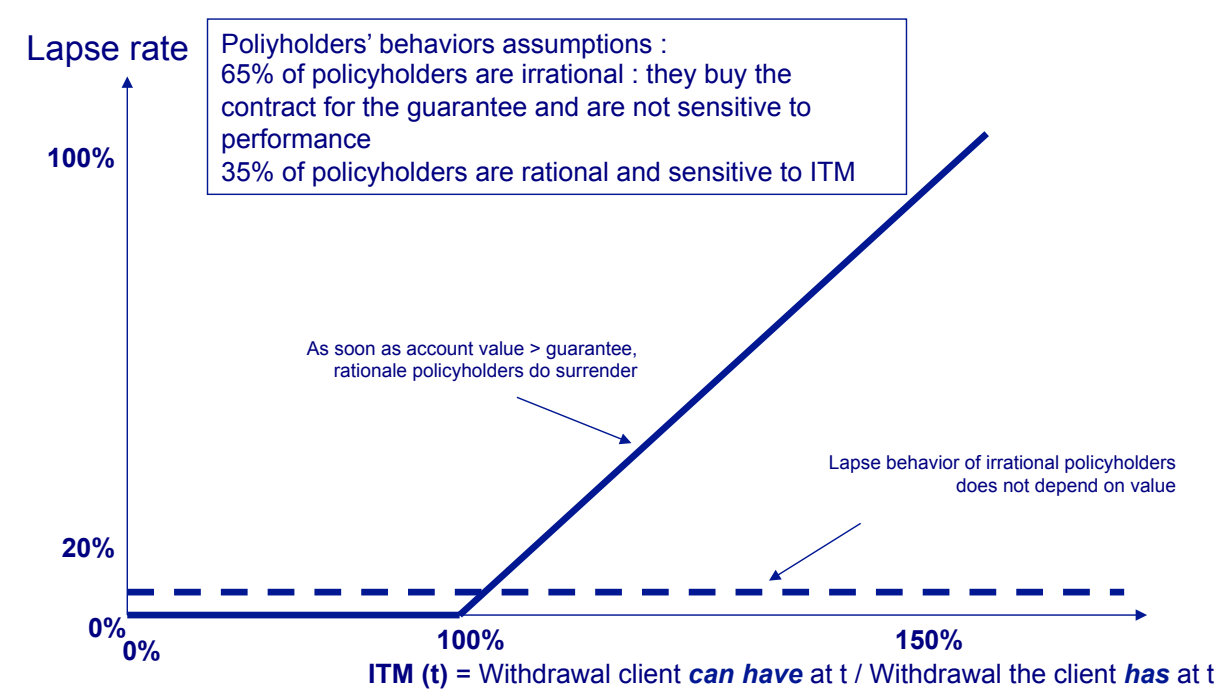

Figure 2. Example of a dynamic linear function. 


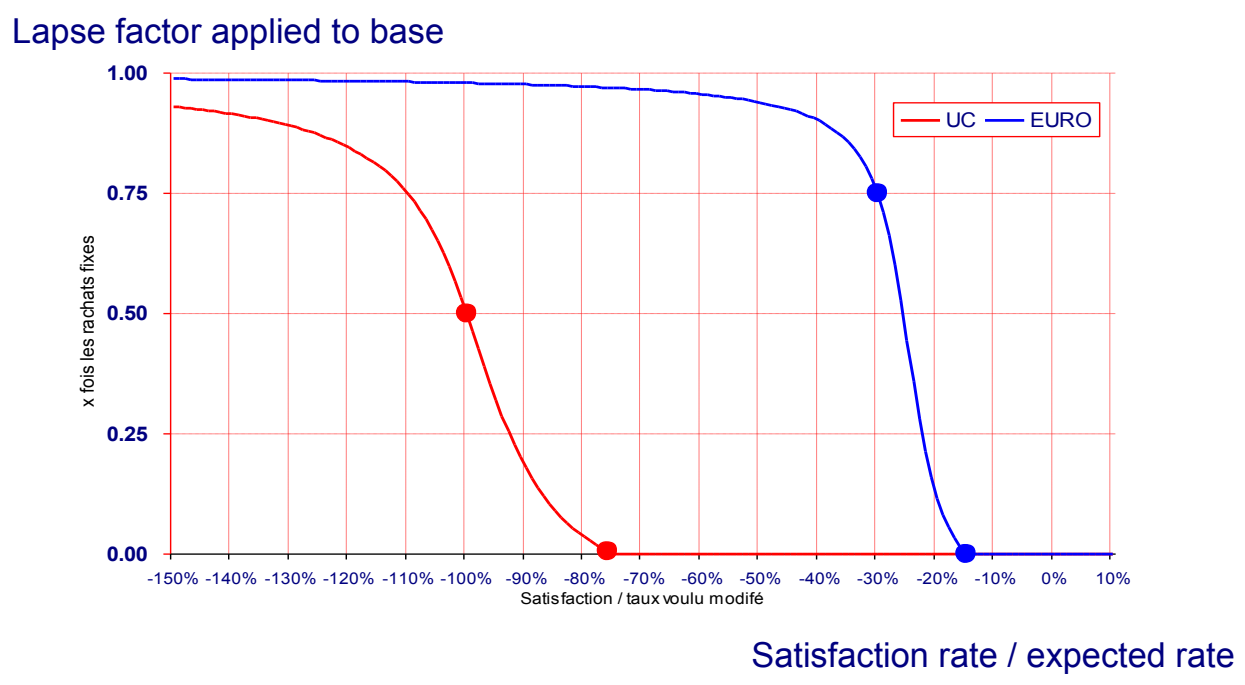

Figure 3. Example of a dynamic arctangent function.

\section{Why do GLM tend to be unsatisfactory ?}

For many reasons it would be tempting to apply these "dynamic" functions on a static table, altough this is clearly not the best way to incorporate the impact of an external environment. For example, the time lag between the adjustment and its cause may cause errors in forecasting surrender decisions. Moreover the discriminant power of certain risk factors makes the portfolio composition crucial. If the policyholders' characteristics or contract features differ sufficiently from the past, the surrender decisions should change significantly. Hopefully, regression techniques can deal with all these considerations: time dependent variables (e.g. interest rate, unemployment rate) as well as endogenous effects can be handled in the so-called covariates. Kim (2005) was the first to take advantage of GLM dynamic properties to model surrenders (with promising results); but as we shall argue below, this method does not give satisfying results in most of applications.

To illustrate this, we have performed an analysis on Endowment products (named "Mixtos") in Spain. These saving contracts have a great popularity despite their relative high premiums, due to the double guarantee at maturity (benefit whatever the situation, death or survival). Our database provides us with some information on the policyholders (gender, birth date, face amount, premium) and on the contracts (product id, profit-sharing option, premium frequency, issue date, termination date, lapse reason). Lapse reasons encompass death, maturity, cancellation and surrender. The face amount represents somehow the policyholder's wealth, and the premium equals the risk premium added to the saving premium. The risk premium is the probability for the guarantee to be triggered multiplied by the sum-at-risk (sum paid back to the policyholder in this case). For example if the product covers death, the 
risk premium is the mortality rate multiplied by the discounted sum-at-risk (reserve in case of death). The saving premium is basically the policyholder's investment.

The whole observation period (in which the portfolio is at maturity) is divided into months. Each month, the policyholders' updated characteristics are listed while the contracts remain in force: we get 991010 observations from 28506 policyholders. This way, the policyholders can wonder more than once a year (actually twelve) whether they should surrender. Nevertheless, it imposes a very strong assumption: the decision to surrender at date " $t+1$ " is independent of the decision at " $t$ " (or before). Furthermore early lapsers' characteristics will be less represented than others, creating a selection bias. Anyway, the comparison between regression coefficients from a Cox proportional hazard survival model (Cox (1972)) and ours indicate that it is negligible. This is because early surrenders are commonplace on this product family.

The whole sample is split into a two-third sized learning sample to build the model (from 01/2000 to 03/2005; 659357 data points), and a one-third sized test sample (from 04/2005 to 12/2007; 361653 observations). This temporal split aims at validating the relevance of predictions in various economic contexts, as well as the accuracy of the model fit to the data. This process should ensure robustness of further simulations.

Since the surrender decision is binary, we choose a logistic link in the GLM family. In the following case study, the logit inputs are the seasonality via the observation month, the financial conditions via the $10 \mathrm{Y}$ bond rate (more precisely its three last values to define the "lookback period", denoted by delta), and the three most significant structural risk factors obtained by CART (an interesting algorithm for discriminant analyses, see Breiman et al. (1984) and section 3): the contract duration (time elapsed since the issue), the risk premium and the profit-sharing option. Deaths are neglected because the average mortality rate equals $2 \times 10^{-4}$. Figure 4 shows that the prediction of aggregated individual surrender decisions looks acceptable on the learning period; whereas it is rather bad on the validation one. Actually the model is globally significant when considering goodness-of-fit criteria such as Wald tests, hypothesis tests or deviance. Nonetheless, it seems to give wrong predictions in extreme situations (in 2007). The market downturn may have made the importance of risk factors change, rebalancing the weights lent to structural (seasonality, contract duration, profit-sharing option) and temporal covariates (10Y bond rate). Although the former should be mostly predominant, we think that the latter has a stronger impact in case of a crisis. In addition, the independence assumption between policyholders is rather questionable in this context. The sudden and sharp drop of the surrender rate in figure 4 is very likely to come from copycat behaviours (Biard et al. (2008)). In life insurance, Loisel \& Milhaud (2011) model it with a Mardia copula, which mecanically intensifies the drop (or rise) of the surrender rate by common shocks.

As a matter of fact the logit model cannot capture the brutal level change 

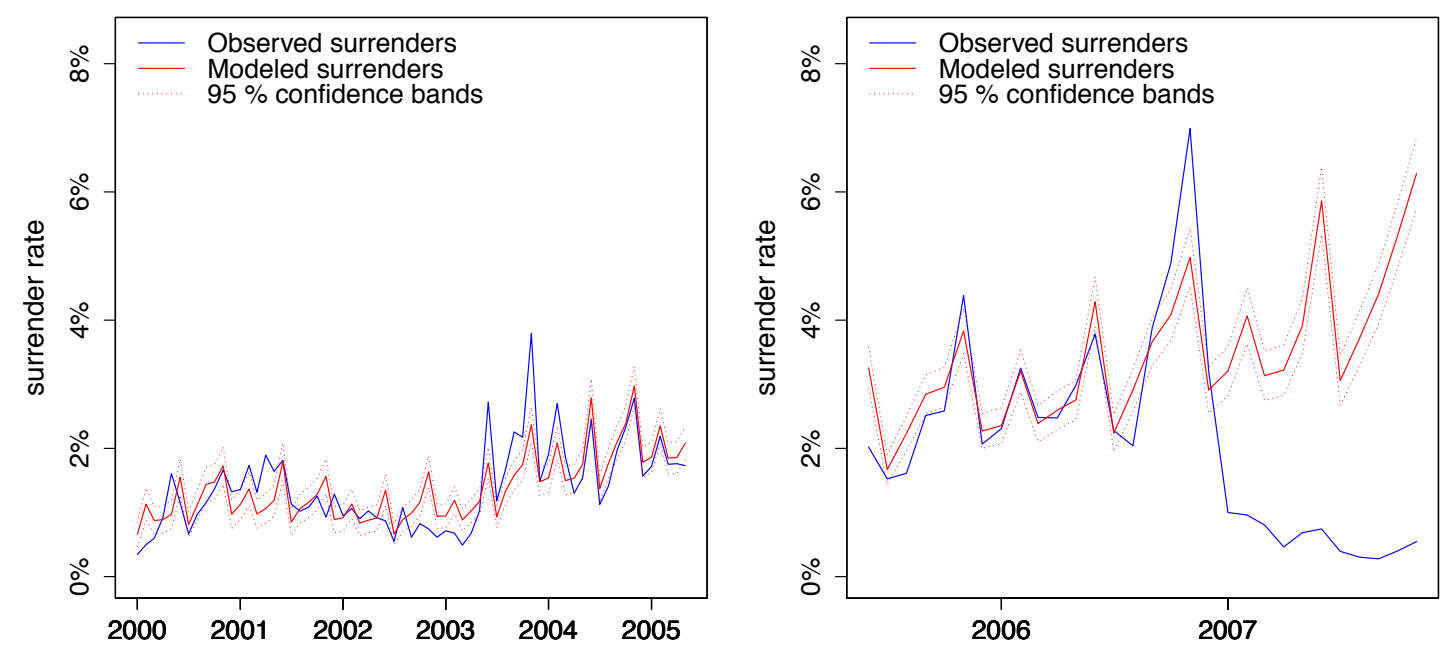

Figure 4. Monthly predictions of the surrender rate (left: learning sample, right: validation sample) by a logit model. Endowment contracts.

experienced in 2007, because exogenous effects were clearly underestimated. $G L M$ usually fail into predicting surrender decisions since they force too much structure on the data, leading to problems such as overdispersion. To put it in a nutschell, GLM give satisfactory results as long as the economic conditions slightly differ from the past, otherwise they do not: this big drawback prevented professionals from using them to manage the surrender risk, which explains why they were not further developed in practice.

\section{A new methodology to manage the surrender risk}

We saw in the previous sections the two major issues: selection of significant risk factors, heterogeneity of policyholders' behaviour and potential correlation between them.

As mentioned before, the CART algorithm is a good candidate to select salient features of the data without assuming any relation between the outcome and the explanatory variables. CART, which stands for "Classification And Regression Trees", iteratively segments the population and provides for the importance of predictors in a discriminant analysis. Then a resampling technique called "random forests" (Breiman (2001)) is used to improve the robustness of this ranking. Concerning the second point, finite mixture models extend classical GLM and allow to handle such hindrances: in particular, policyholders' opposite reactions to the same event can be represented by a multimodal density function.

Other exogenous factors such as company reputation or marketing plans can also deeply influence policyholders' decisions, but they are unmeasurable! 


\subsection{Finite Mixture Models in two words}

Finite mixtures are a highly flexible semiparametric technique to approximate unknown distributional shapes (McLachlan \& Peel (2000), p.12). Areas in which they have been successfully applied include marketing, economics, astronomy, biology and medicine among many others. Theoretical developments mainly exist for mixtures from the exponential family, especially gaussian mixtures. In the sequel we quickly present some important notions of finite mixture modelling, without going into great detail. The reader is referred to Frühwirth-Schnatter (2006) or McLachlan \& Peel (2000) for a comprehensive technical account on these topics.

For us, the surrender decision of the $j^{\text {th }}$ policyholder is represented by the random variable $Y_{j}$, whose mixture density is given by $f\left(y_{j}\right)=\sum_{i=1}^{g} \pi_{i} f_{i}\left(y_{j}\right)$. $g$ stands for the number of components in the mixture, $f_{i}\left(y_{j}\right)$ is the density of the $i^{t h}$ component, $\pi_{i}$ its weight with the natural constraint $\sum_{i} \pi_{i}=1$. The goal is to infer from data the estimation of $g ; \pi_{i}$, possibly depending on some covariates and representing the probability to belong to component $i$; and $f_{i}$, which can originate from different parametric families. In our framework, the density of the $i^{\text {th }}$ component for the $j^{\text {th }}$ observation reads

$$
f_{i}\left(y_{j}\right)=f\left(y_{j} ; p_{i j}\right)=\mathbb{P}_{i}\left(Y_{j}=y_{j}\right)=C_{N_{j}}^{y_{j}} p_{i j}^{y_{j}}\left(1-p_{i j}\right)^{N_{j}-y_{j}}
$$

giving a logit mixture at the end.

$N_{j}$ is the size of the $j^{t h}$ homogeneous group (policyholders with the same characteristics), $y_{j}$ is the number of surrenders in group $j$, and $p_{i j}$ is the probability to surrender of group $j$ in the $i^{\text {th }}$ component, with

$$
p_{i j}=\frac{\exp \left(\beta_{i}^{T} x_{j}\right)}{1+\exp \left(\beta_{i}^{T} x_{j}\right)} \quad \text { and } \quad \pi_{i j}=\frac{\exp \left(\gamma_{i}^{T} x_{j}^{\prime}\right)}{\sum_{h=1}^{g} \exp \left(\gamma_{h}^{T} x_{j}^{\prime}\right)} .
$$

$x_{j}$ and $x_{j}^{\prime}$ are the covariates, or in other words the individual characteristics. Intuitively there exists $g$ subsets in the whole population, each one in proportion $\pi$ and with different sensitiveness $f_{i}\left(y_{j}\right)$. Many authors use finite mixtures as a model-based clustering, since each observation is assigned a component of the mixture (once fitted). Of course some conditions have to be satisfied when using this model class; typically about the identifiability and the properties of the maximum likelihood estimation. In our context, we fulfill the requirements for the applicability of such models.

\subsection{Illustration on endowments}

To build the mixture, we use the same data as in section 2 in order to compare both regression models. For example, the learning period still represents two- 
third of the total sample. The risk factors and the replication process are identical, except that the data set is shortened by setting a quarterly time step (for the fitting to be less time-consuming). The following case study aims at illustrating the successful methodology that will be adopted in further applications.

We firstly perform a descriptive analysis of the portfolio to get some clues about how to model surrenders. We are particularly interested in statistics that describe the evolution of the portfolio, and thus are useful to get an impression of the portfolio heterogeneity.

Figure 5 shows the exposure, the surrender rate and the lapse rate path. The surrender rate is quite low and stable in 2000-2003, but goes up the next three years. A peak is then observed in 2007, followed by a stunning drop even though the exposure remains high. Regular (and much smaller) peaks and dips indicate seasonal trends, which will be input in the model due to the covariate "end.month".

Tax constraints or penalty fees usually encourage policyholders to lapse at some specific dates, as can be seen on figure 6 representing the surrender rate in function of the contract duration. Here the contracts can be surrendered at each anniversary date without any fee, which causes the annual peaks. Given that this curve is not monotonic, one had better transform this continuous variable into a qualitative one. All further categorizations will be performed via the quantile method, which maintains a similar exposure in built classes.

An exponential smoothing on figure 6 should result in a decreasing surrender rate as the contract duration increases: hence the global surrender rate of old cohorts (e.g. underwriting in 2002) should globally be higher than for recent

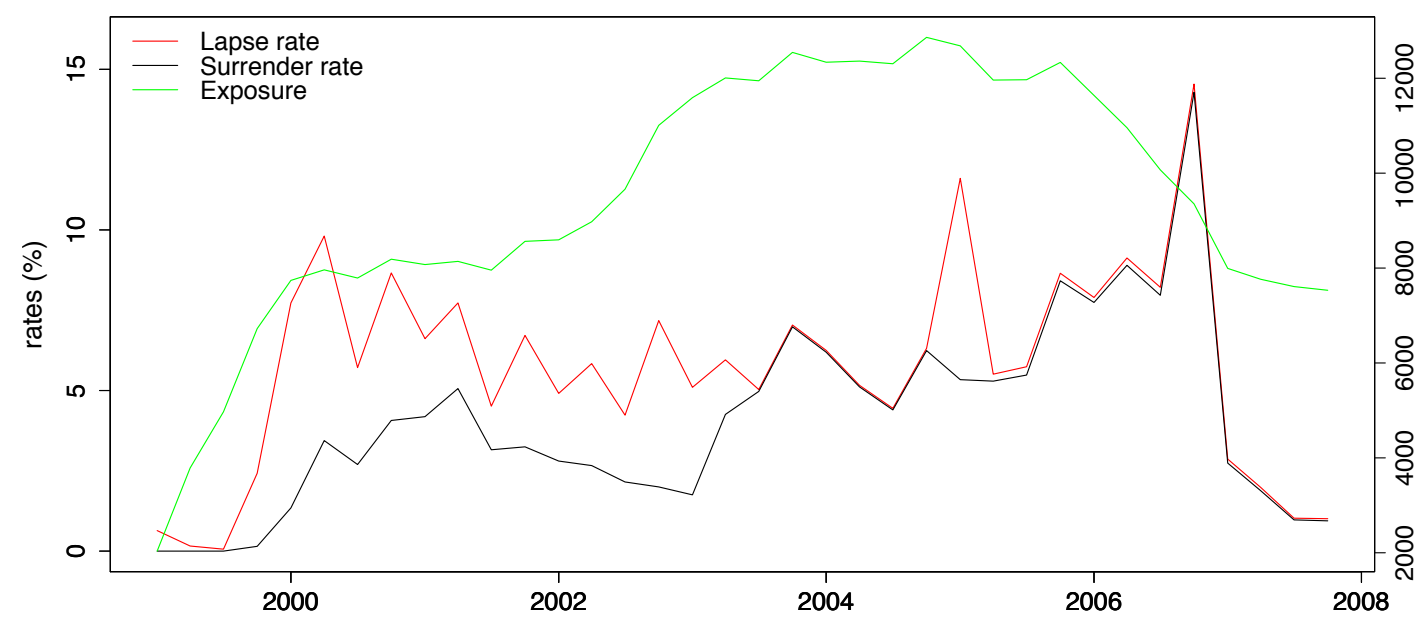

Figure 5. Exposure and quarterly surrender rate of endowments (lapses include deaths, maturity, cancellations and surrenders). 


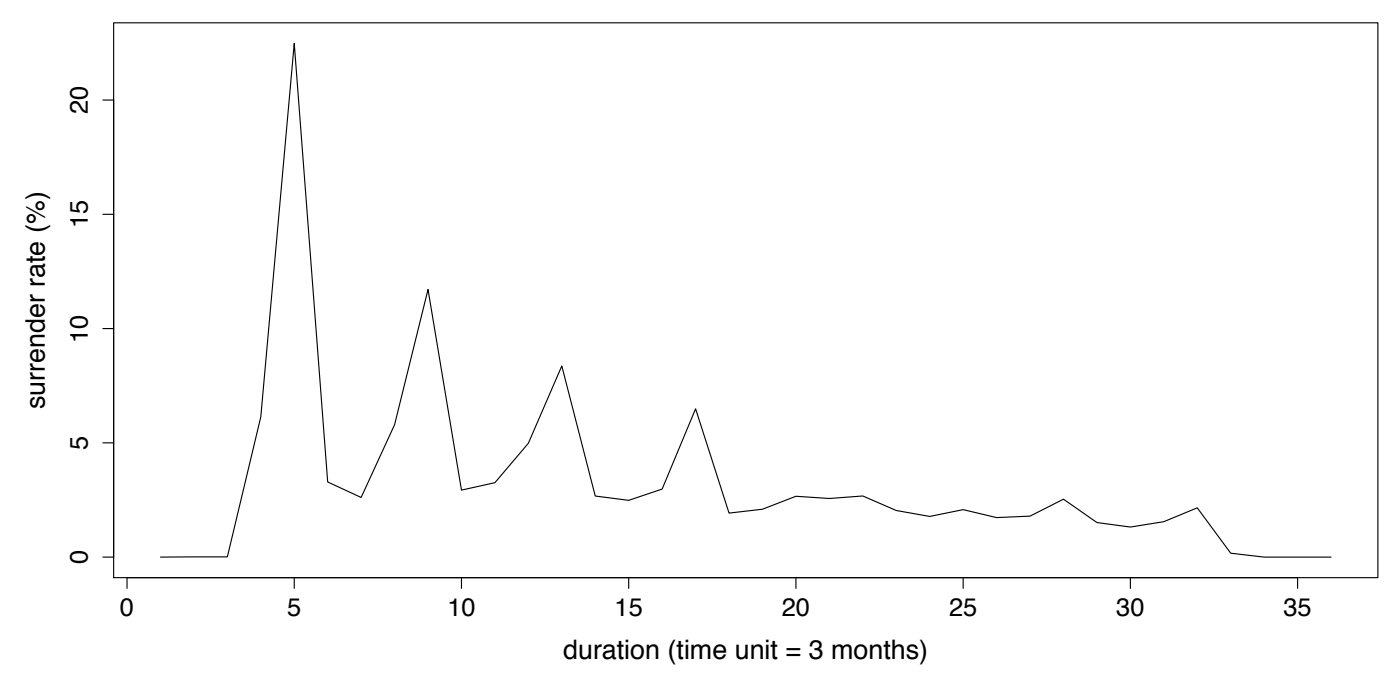

Figure 6. Surrenders versus contract duration (quarterly basis) on endowments.

ones (e.g. underwriting in 2006). In practice figure 7 shows the opposite $(80 \%$ versus 30\%)! Although there is no clear reason for these cohort effects, we think that it may be due to marketing plans or regulatory changes. To investigate this, we could look at cross-effects between the duration and the date. Figure 8 allows us to see an evolution in 2002: actually the general terms of " Mixtos" were changed and the opportunity to surrender at each anniversary date without any fee was set up there. The heterogeneity thus partly comes from the mixing of these two different populations in the portfolio.

Up to now, we highlighted the key role of the seasonality and the contract duration. Other important risk factors can be extracted thanks to the CART algorithm, which gives an overview of other variables that could be taken into account. Figure 9 steers this choice: the profit-sharing option (named "PB.guarantee") and the risk premium seem to be highly significant (it is confirmed by the descriptive analysis). The risk premium will be categorized

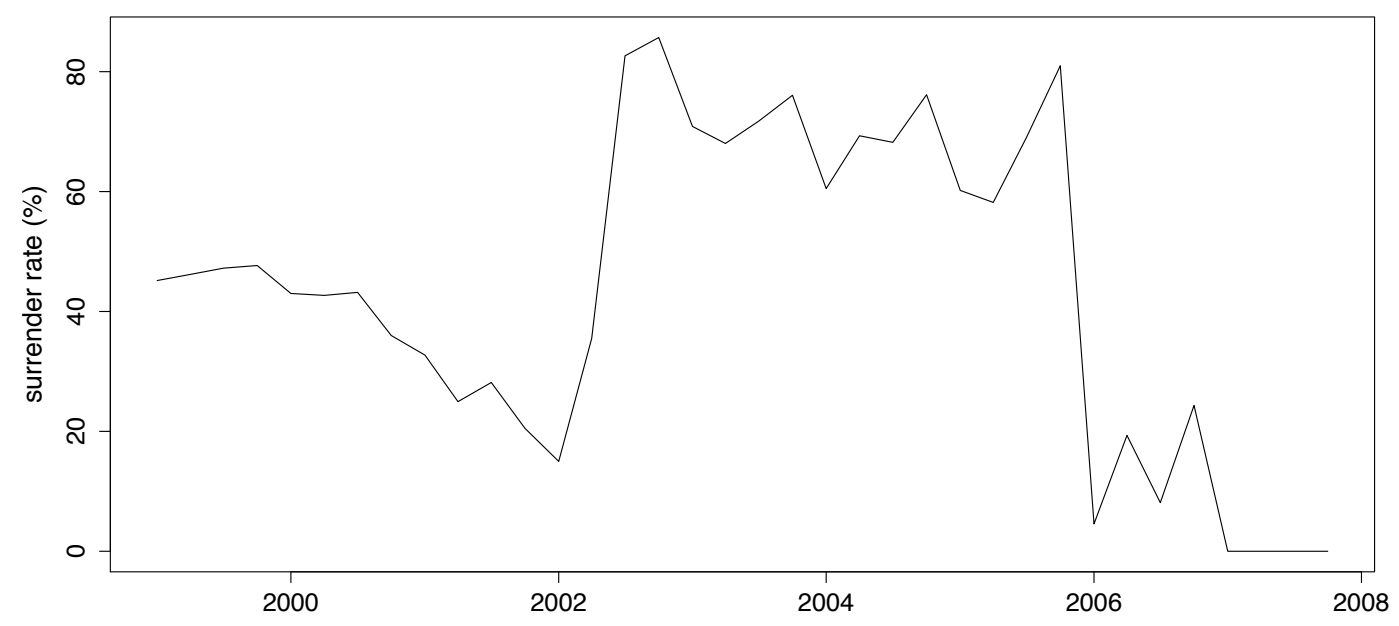

Figure 7. Global surrender rate by cohort on endowments. 


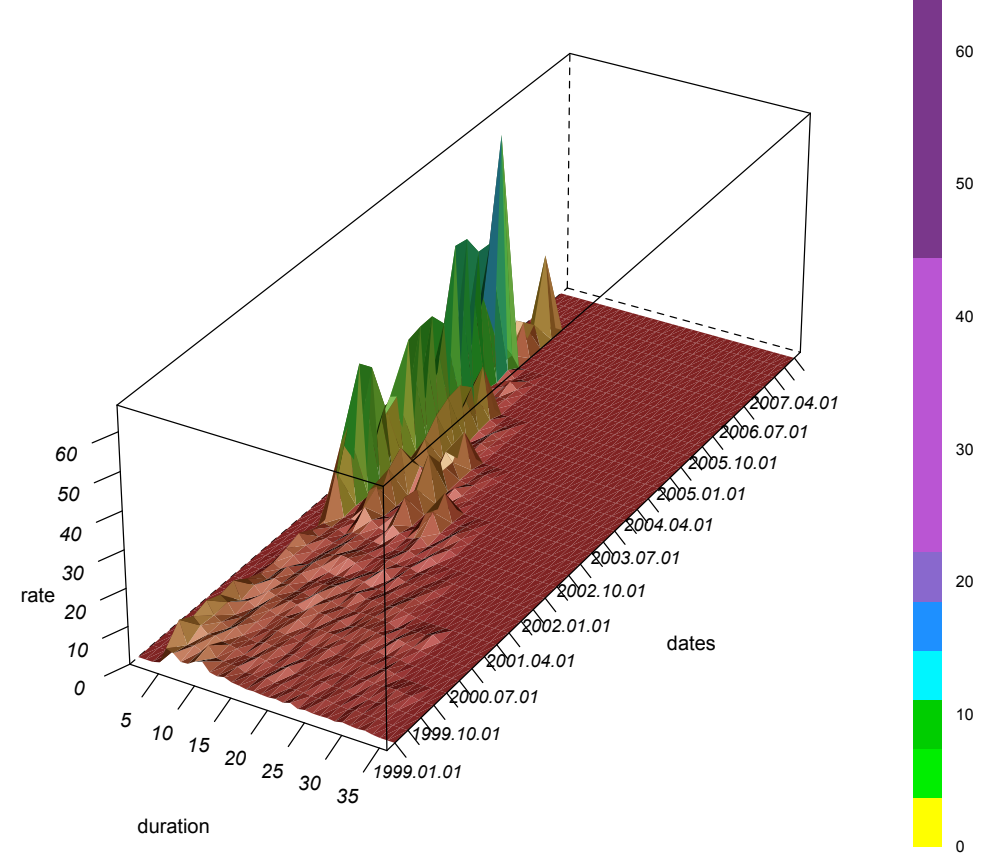

Figure 8. Quarterly surrender rate (\%) by date and contract duration, endowments.

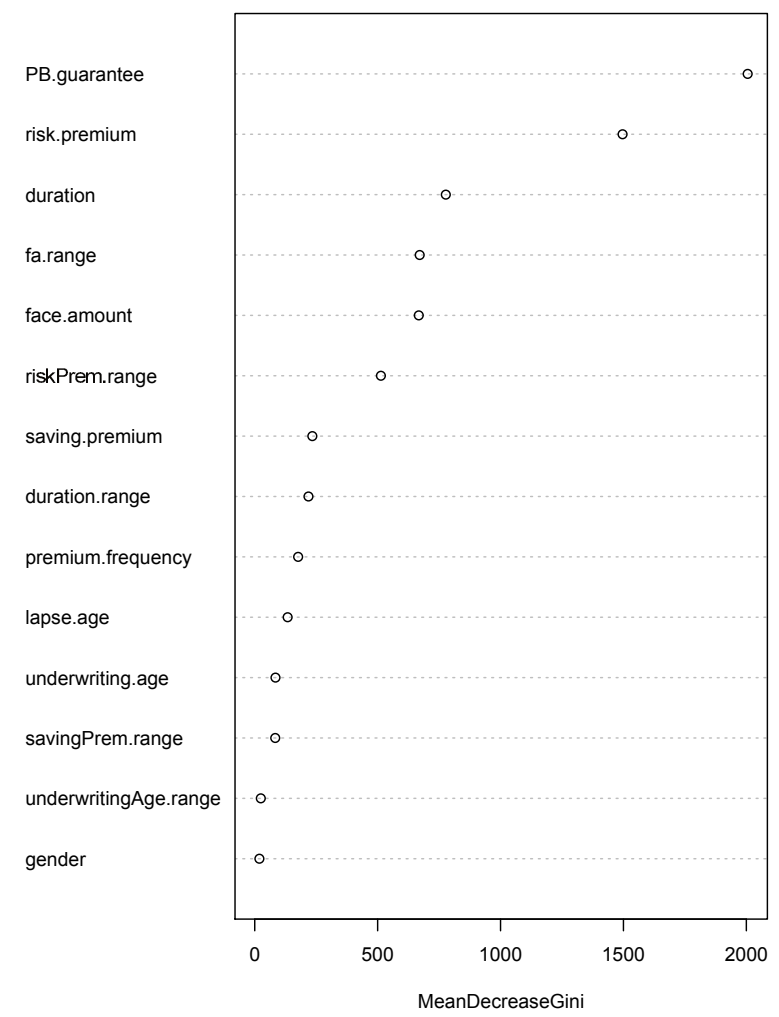

Figure 9. Importance of risk factors by random forests, endowments. The higher the decrease of the Gini index is, the more significant the explanatory variable gets (in a discriminant analysis). 
because of its non-monotonic relation with the surrender rate. Henceforth, we a priori know the main covariates that should be input in the regression model.

Modelling and predicting with $\boldsymbol{G L} \boldsymbol{M}$ mixtures Figure 10 has already been extensively analysed in section 2 . Just notice that a quarterly time step tends to give worse predictions than a monthly one. Anyway our concern is mainly to capture the unexpected level change observed in 2007. To achieve this, we fit logit mixtures from two to five components and select the model with the lowest BIC (Schwarz (1978)). This criterion penalizes the likelihood of the model with a complexity cost linked to the number of parameters. In the sequel we give a complete description of the mixture (estimated parameters and weights), including comments about some practical interpretations.

The "best" mixture for endowments has five components (see table A.1 in appendix), which is in line with the high heterogeneity that was initially observed. To test qualitatively the relevance of the mixture modelling, we plot on figure 11 the aggregation of predicted individual decisions with the backtesting approach: the model perfectly fits the data, has a strong predictive power and looks robust (the confidence interval narrows down). The key is to distinguish between endogenous and exogenous risks. Our intuition is that the heterogeneity may not come from structural factors since they should identically affect all the policyholders, unlike cyclical effects. For instance the whole population, whatever its characteristics or contract options, is subjected to the same fiscality constraints. Therefore, why not force the regression coefficients corresponding to these effects to be equal in every component? This also enables to limit the number of parameters to estimate. On the contrary, the different sensitivenesses to market breakdowns suggest leaving the estimation of other parameters free. Finally the individuals are assigned a group depending on their base surrender risk and how they react to temporary risk factors. Figure 12 (and table A.2 in appendix) provides for the estimated regression coefficients of the five groups resulting from the mixture, with following effects:

- structural (equal in every component): a weak seasonality of the surrender decisions is detected (low regression coefficient), with increasing trends at the end of the calendar year. The effect of the contract duration is clear: most of surrenders are concentrated between the fifth and the twelvth quarters ("middle range" category). Contracts without profit-sharing option are much less likely to be surrendered (once again confirmed by descriptive statistics).

- cyclical: according to the marketing teams, the risk premium effect (correlated to the wealth of policyholders) shows that people react on a relative scale. Indeed, the groups whose risk premium is highly significant are more sensitive to $10 \mathrm{Y}$ bond rate movements. 

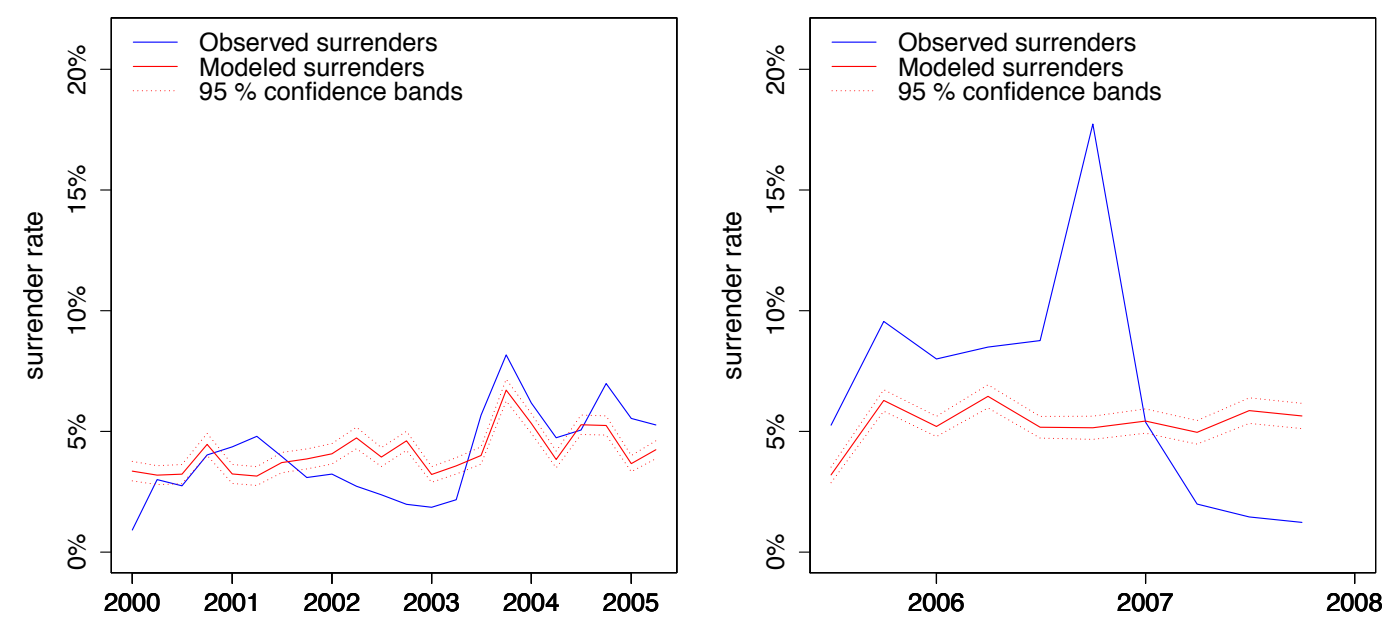

Figure 10. Quarterly predictions of the surrender rate by a logit model (left: learning sample, right: validation sample). Endowment contracts (Mixtos).
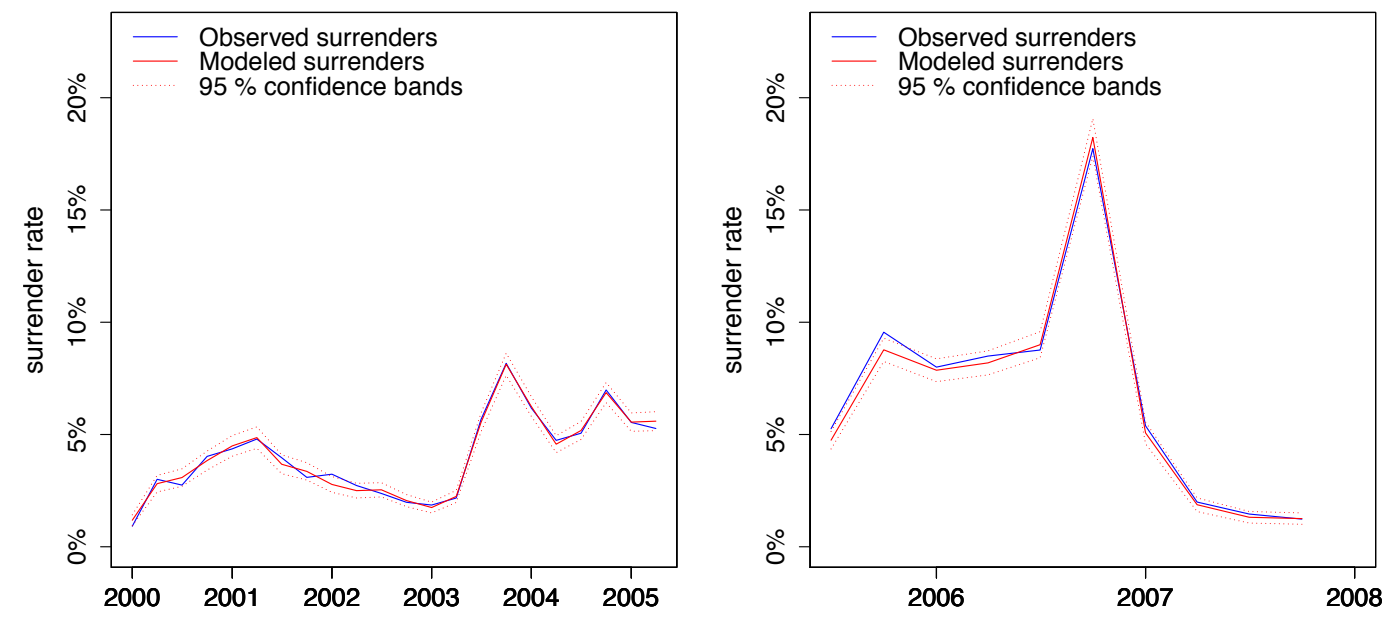

Figure 11. Quarterly predictions of the surrender rate by a logit mixture (left: learning sample, right: validation sample). Endowment contracts (Mixtos).

- correlation: the impact of the $10 \mathrm{Y}$ bond rate is quite strong, and makes the component densities be simultaneously adjusted every quarter. The fit reveals that some policyholders surrender more when this rate goes up (components 1, 2, 3 and 5), unlike the ones belonging to component 4. Most of policyholders thus behave rationally (recall that the profitability is fixed for Mixtos).

The standard deviation of the estimated regression coefficients proves that the fitting is robust. Indeed zero does not belong to the confidence intervals, meaning that this choice of risk factors is relevant. Equation (1) on $\pi_{i j}$ allows to determine the component weights $\pi_{1}, \ldots, \pi_{5}$ from the estimated intercepts (see table A.2, no covariate in weights here), respectively equal to $22 \%, 23 \%$, $24 \%, 10 \%$, and $21 \%$. We justify by these values that each component plays its own role. 




Figure 12. Regression coefficients for each component of the mixture model.

Other tests to check for the robustness of the model have been successfully performed (gaussian residuals by Pearson test, and non-parametric test by Wilcoxon Mann-Whitney).

To sum up, we propose here a methodology to take into account the different risk factors. The key idea is to split them into endogenous (structural) and exogenous (temporary) risks. The mixture then enables great improvement of the model flexibility by allowing a multimodal density for the behaviour. In the last section we apply this methodology on various contract families, and try to see wether it could be validated.

\section{Other applications}

A real life insurance portfolio is dedicated to this analysis. Our purpose is to see whether the methodology works on a wide product range, from pure savings to contracts embedding protection riders, throwing in unit-links along the way. We run the studies by product family, although another choice (e.g. product id) would have been potentially interesting. This decision is motivated 
by an Asset and Liabilities Management (ALM) perspective: actually it would have been impossible to calibrate all the correlations between single products, in order to get the aggregated loss due to surrenders over the whole portfolio. For each family, we give the predictions with both approaches (logit and logit mixture) without too many details for the sake of conciseness. Selected risk factors are available in table 2, numerical estimations as well as comprehensive interpretations can be found in Milhaud (2011).

Ahorro To start with, we study the "Ahorro" family whose guaranteed return makes the insurer bear the interest rate risk. As can be seen on figure 13, the results by the logit are extremely bad.

The reason why the model does not fit well the observed surrender rate is
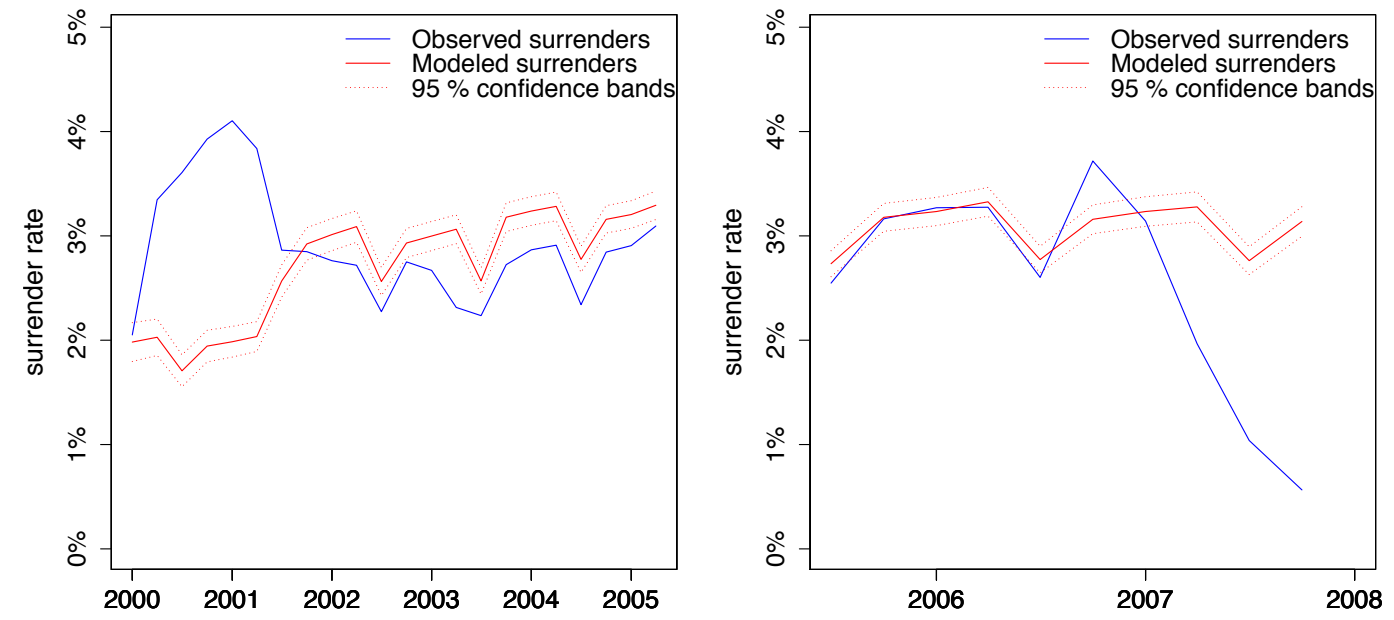

Figure 13. Quarterly predictions of the surrender rate by a logit model (left: learning sample, right: validation sample). Ahorro contracts.
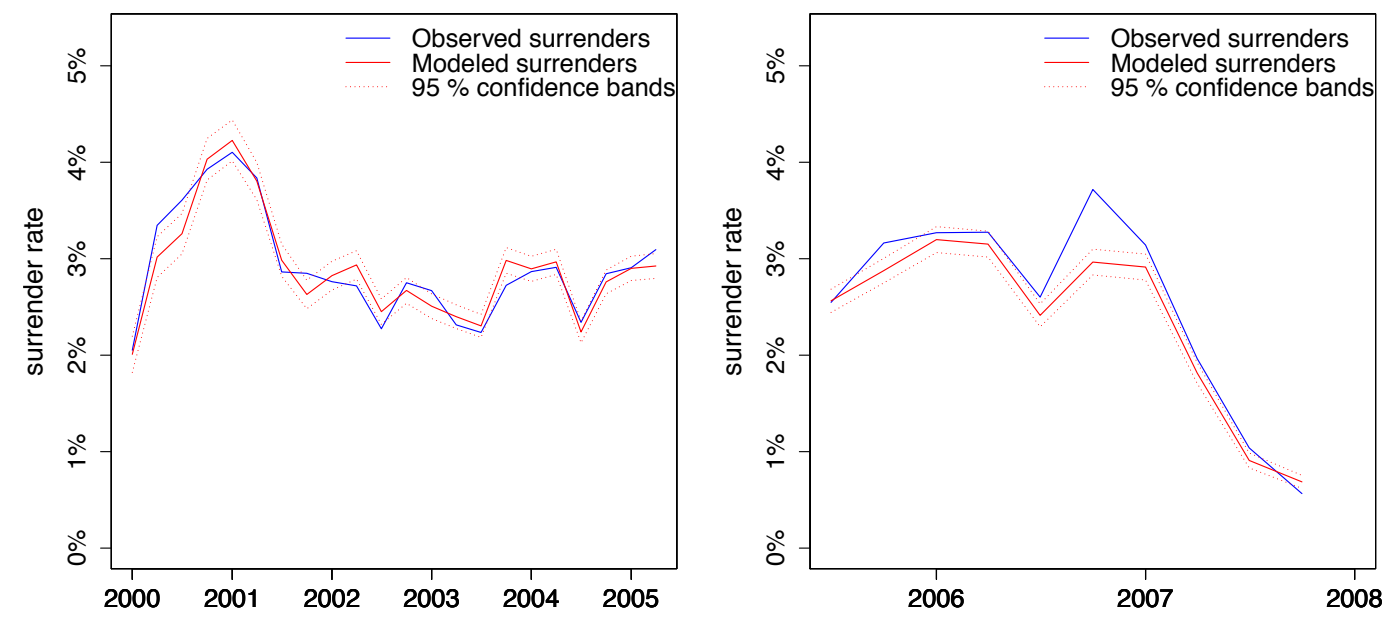

Figure 14. Quarterly predictions of the surrender rate by a logit mixture (left: learning sample, right: validation sample). Ahorro contracts. 
that it does not quantify the real effect of the $10 \mathrm{Y}$ bond rate, whose coefficient absolute value equals 0.06 . This means that the rise (or drop) of this index would almost never affect the individual surrender probability! However, the seasonal effect seems to be captured. As compared to the logit, the mixture of logistic regressions gives much more satisfying results. Predictions on figure 14 seem to match the experience, particularly the trends.

The gap between these predictions comes down to a single number: the $10 \mathrm{Y}$ rate regression coefficient is 10 to 100 times higher (depending on the component) than previously, making the impact of this risk factor become much more realistic.

Unit-Link In this case, the return of the contract depends on the financial market performance. The profitability is thus not guaranteed, meaning that the liquidity risk is carried by policyholders. Cohort effects as well as the volatility of financial markets, directly impacting the surrender rate volatility, make the predictions by logit suffer from a lack of reliability (see figure 15). This is exactly the situation where mixture models can significantly improve predictions, because we need to model policyholders' diverging reactions to market movements so as to reflect reality ! Figure 16 shows that the main effects are captured by the mixture: the observed surrender rate mostly belongs to the confidence interval of predictions. Once again, the intensity of logit regression coefficients has nothing to do with that of the mixture: numerical results reveal that there still remains irrational behaviours, but in a very limited proportion. This is surely due to the presence of advisors, regularly intervening on this kind of products.
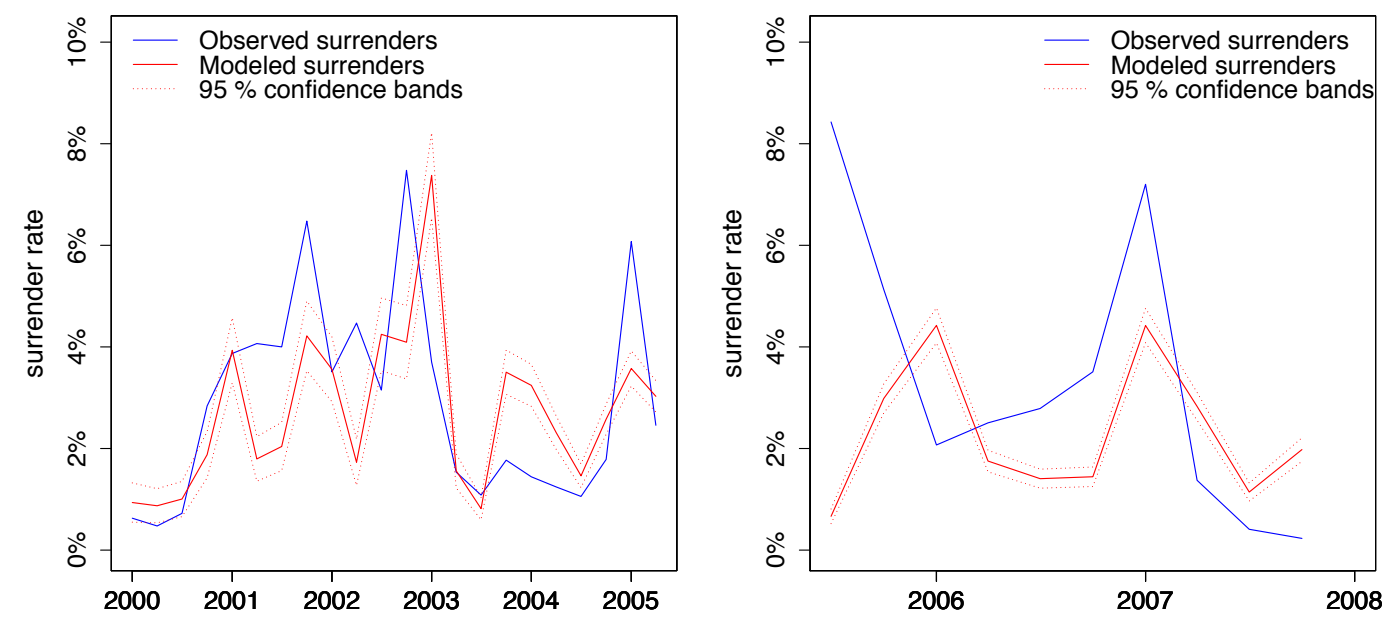

Figure 15. Quarterly predictions of the surrender rate by a logit model (left: learning sample, right: validation sample). Unit-Link contracts. 

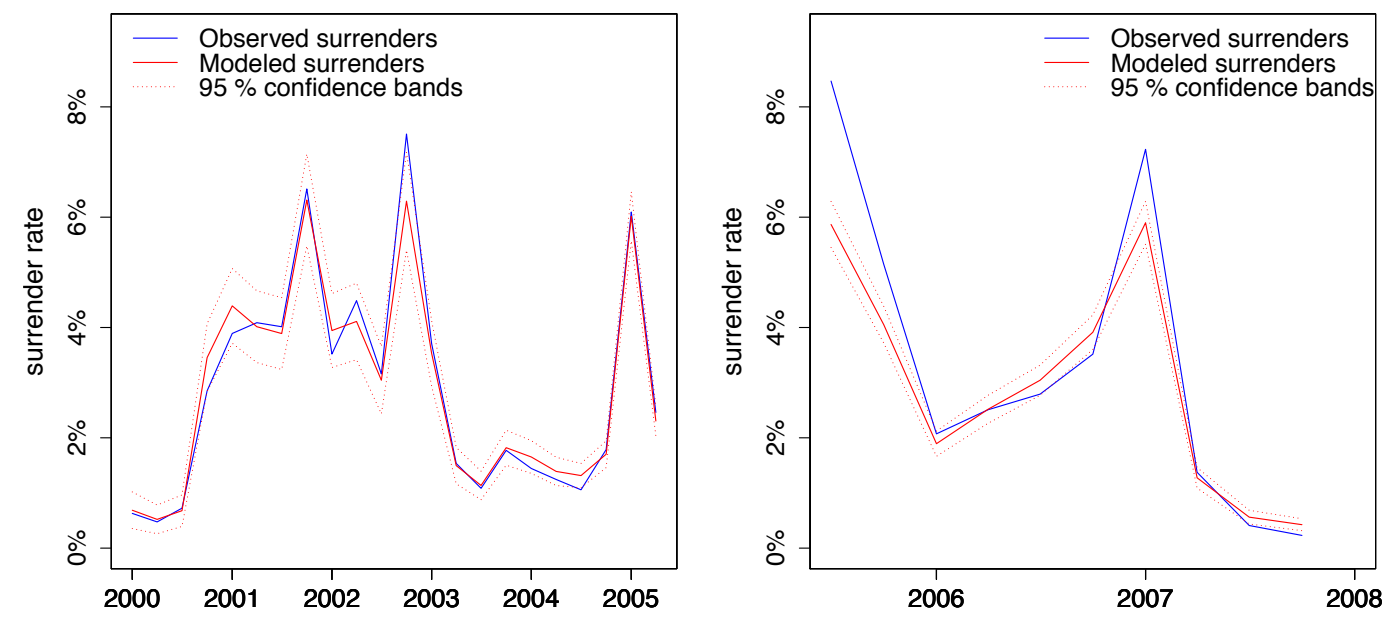

Figure 16. Quarterly predictions of the surrender rate by a logit mixture (left: learning sample, right: validation sample). Unit-Link contracts.

Index-Link Index-link are very close to unit-link products. The difference lies on the investment vehicle, only based on financial indexes for index-link contracts instead of assets for unit-link ones. From this remark, we should roughly have similar results in terms of predictors effects (see table 2). Not surprisingly, the prediction of surrender decisions by the dynamic logit is disappointing irrespective of the considered period. Despite the introduction of economic covariates, the model does not fit the peaks in 2005 and 2006 (figure 17), and the average surrender level in the validation sample does not look appropriate. Conversely, a two-component mixture has a very strong predictive power (figure 18) and is enough to catch the portfolio heterogeneity, proving that the best model is not always the most complex one.
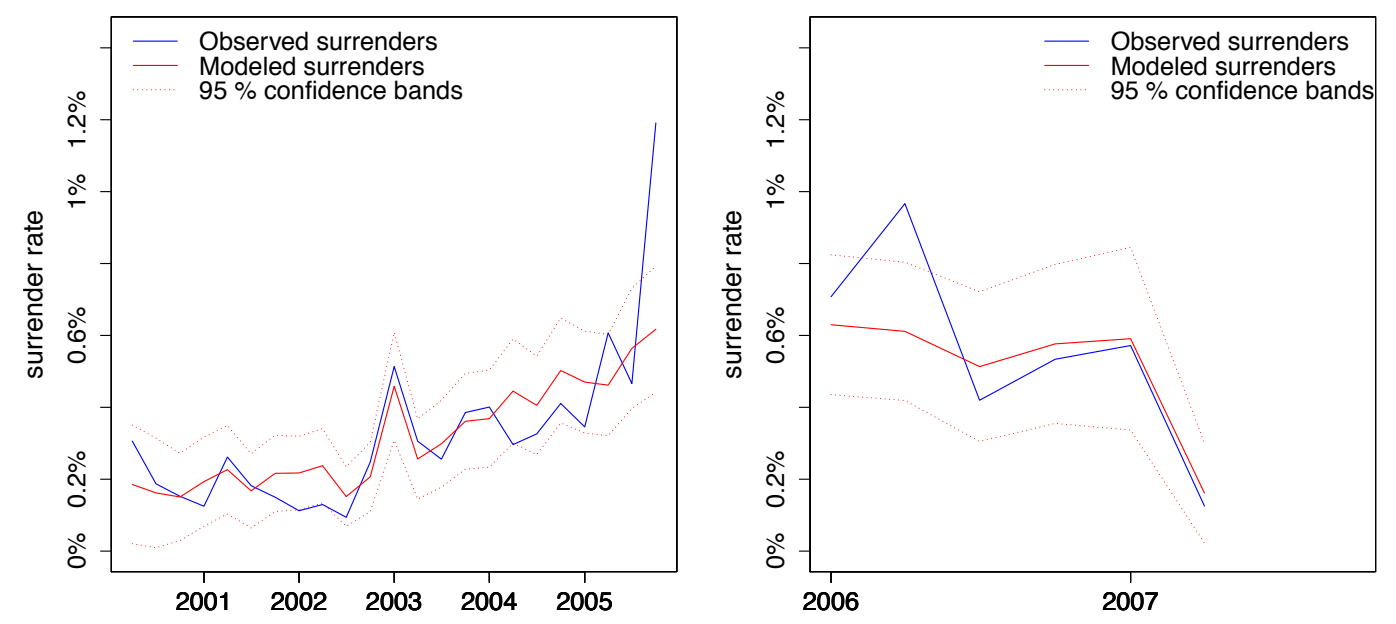

Figure 17. Quarterly predictions of the surrender rate by a logit model (left: learning sample, right: validation sample). Index-Link contracts. 

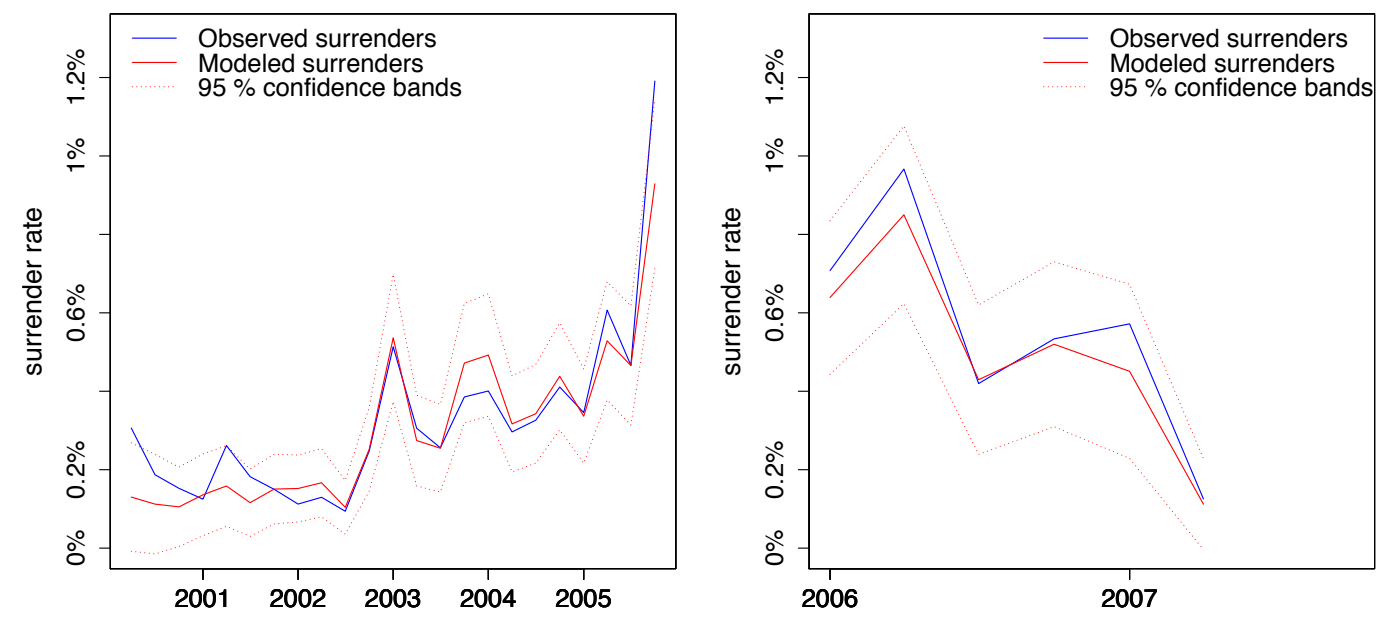

Figure 18. Quarterly predictions of the surrender rate by a logit mixture (left: learning sample, right: validation sample). Index-Link contracts.

Universal Savings Universal savings contracts offer protection riders in addition to a guaranteed return (usually a death or a disability benefit). Those products can be assimilated to pure saving products (Ahorro), except the protection leg which certainly makes the policyholders behave a bit differently. Here the logit model looks efficient to imitate the surrender rate drop in 20082009 (figure 19). The intensity for the cause of this drop is thus well estimated, but the model does not catch with the right amplitude smaller downward (or upward) movements. Is it worth making the model more complex? It obviously depends on our expectations. Although the main risk may have been captured, the modelling is not good enough to set an accurate ALM. However, the mixture perfectly fits the observations on learning and validation periods (figure 20). Moreover, we need not pay attention to the economic context on these products (neither in the logit nor in the logit mixture): it is as
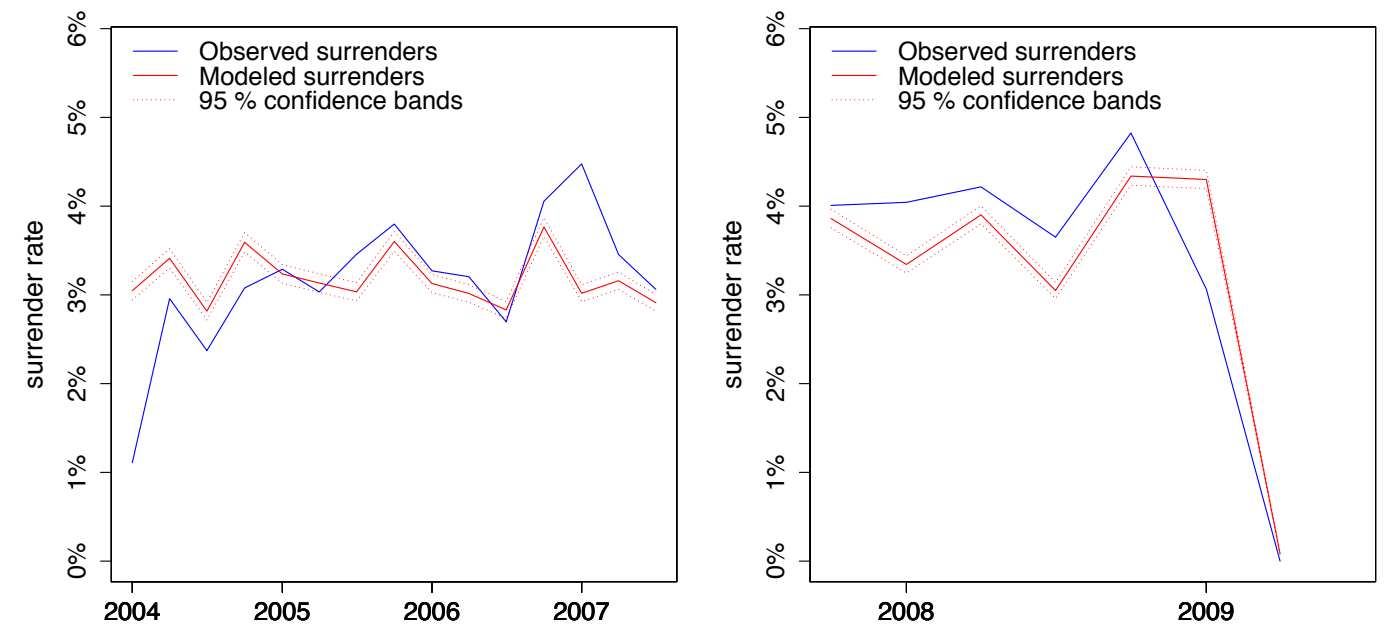

Figure 19. Quarterly predictions of the surrender rate by a logit model (left: learning sample, right: validation sample). Universal savings contracts. 

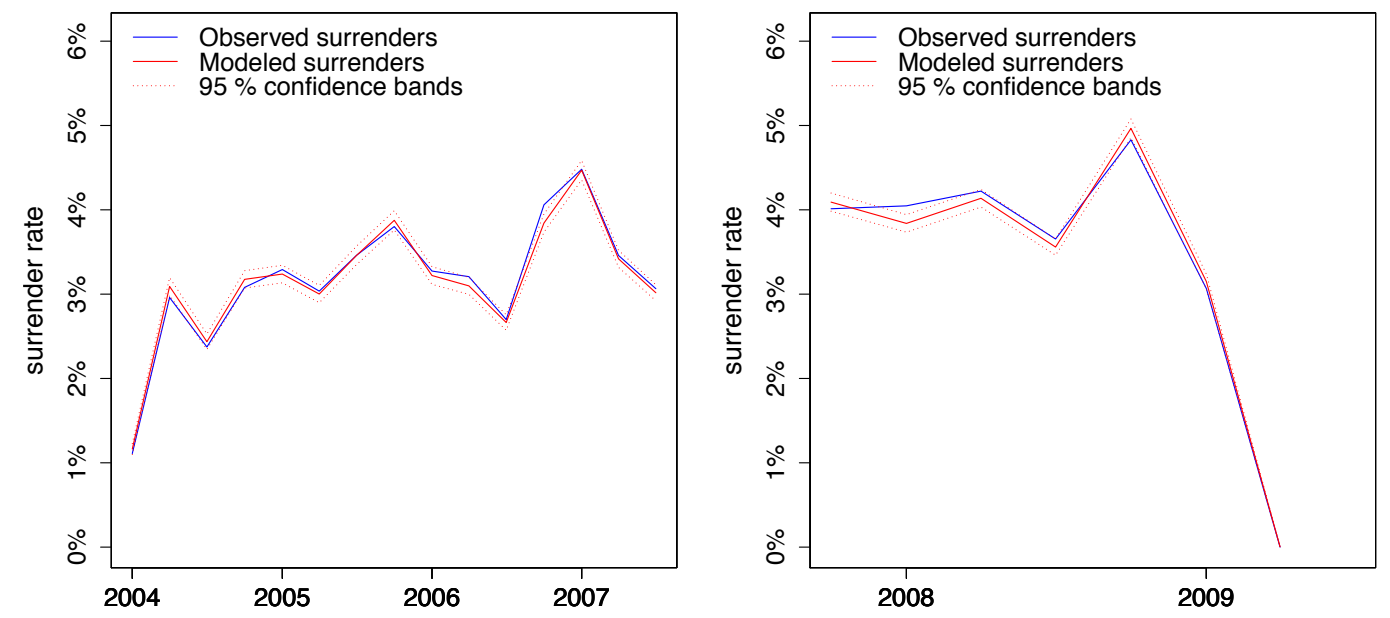

Figure 20. Quarterly predictions of the surrender rate by a logit mixture (left: learning sample, right: validation sample). Universal savings contracts.

if the policyholders consider that the protection leg is more valuable than the saving guarantee. According to the coefficients values of the five components (with respective weights $13 \%, 10 \%, 30 \%, 35 \%$ and $12 \%$ ), the wealth plays a key role to capture the heterogeneity of policyholders' decisions.

Pure Savings The next product family under study is pure savings, very similar to "Ahorro". Following the descriptive analysis, the heterogeneity of surrender behaviour is rather limited; but the logit gives unexpected bad predictions, especially on the validation period (figure 21). Concerning the learning sample, seasonality seems to be captured, although some adjustments would be necessary to get a perfect fit. Once more, figure 22 shows that the mixture is "apt to" predict surrenders on these contracts. However the wrong trend in
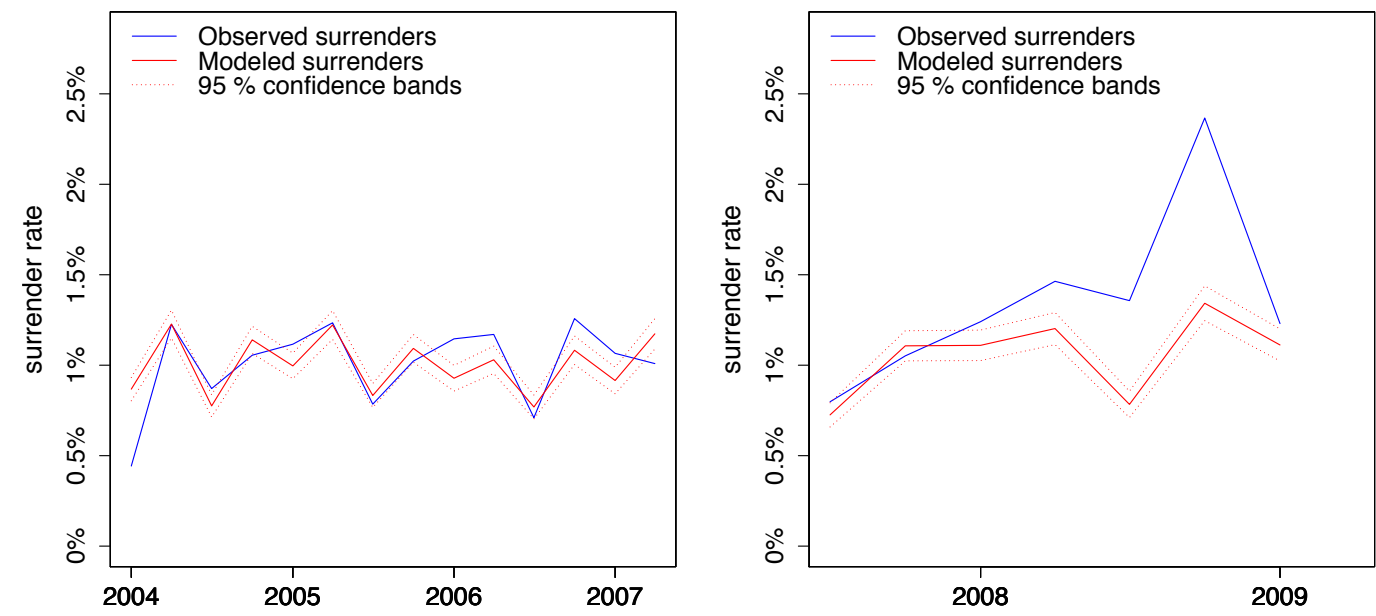

Figure 21. Quarterly predictions of the surrender rate by a logit model (left: learning sample, right: validation sample). Pure savings contracts. 

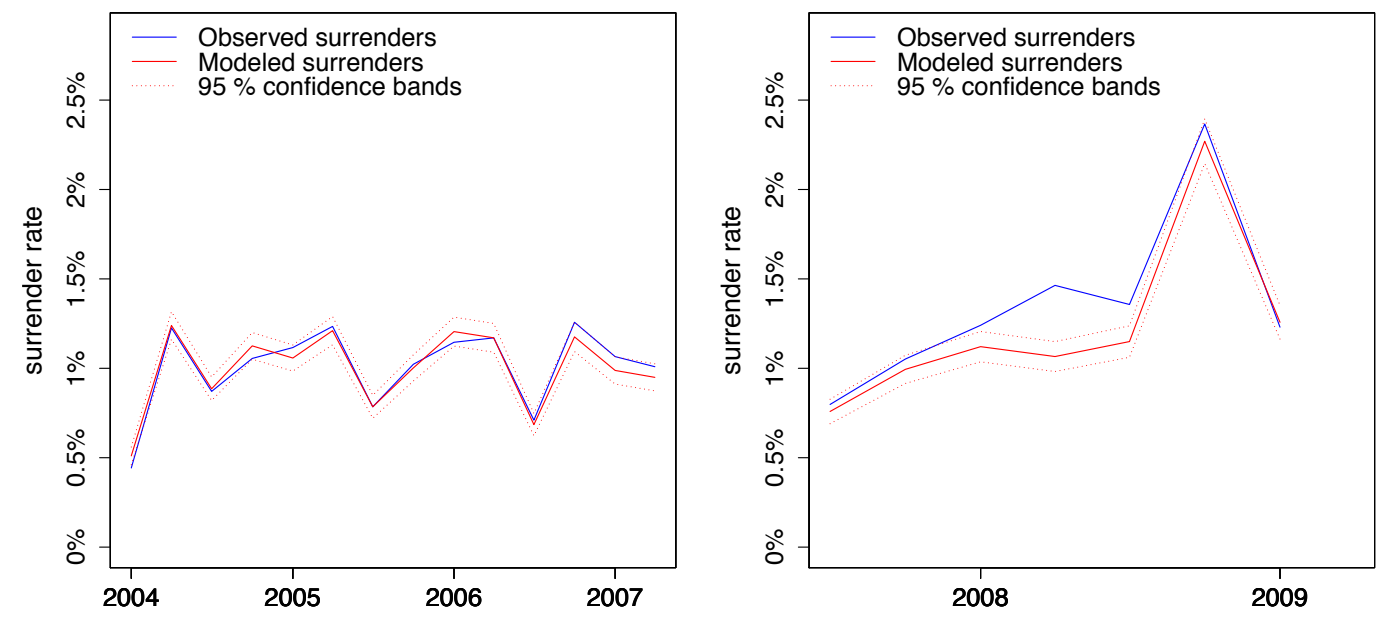

Figure 22. Quarterly predictions of the surrender rate by a logit mixture (left: learning sample, right: validation sample). Pure savings contracts.

2008 markedly underestimates the risk: this is no good news since it means that hidden risky factors were not captured. To be honest, we sought a better model but did not find it; which bears out that the use of mixtures could sometimes not be relevant!

Structured products There are so many different structured products in the database that it would be impossible to exhaustively describe them. They all strongly depend on financial market performance, but each product has its own features. These products are generally designed to meet as much as possible policyholders' needs. Because of their heterogeneity, the logit mixture (figure 24) fits much better the data than the dynamic logit (figure 23). On the back-testing sample (validation period), the observations never belong to
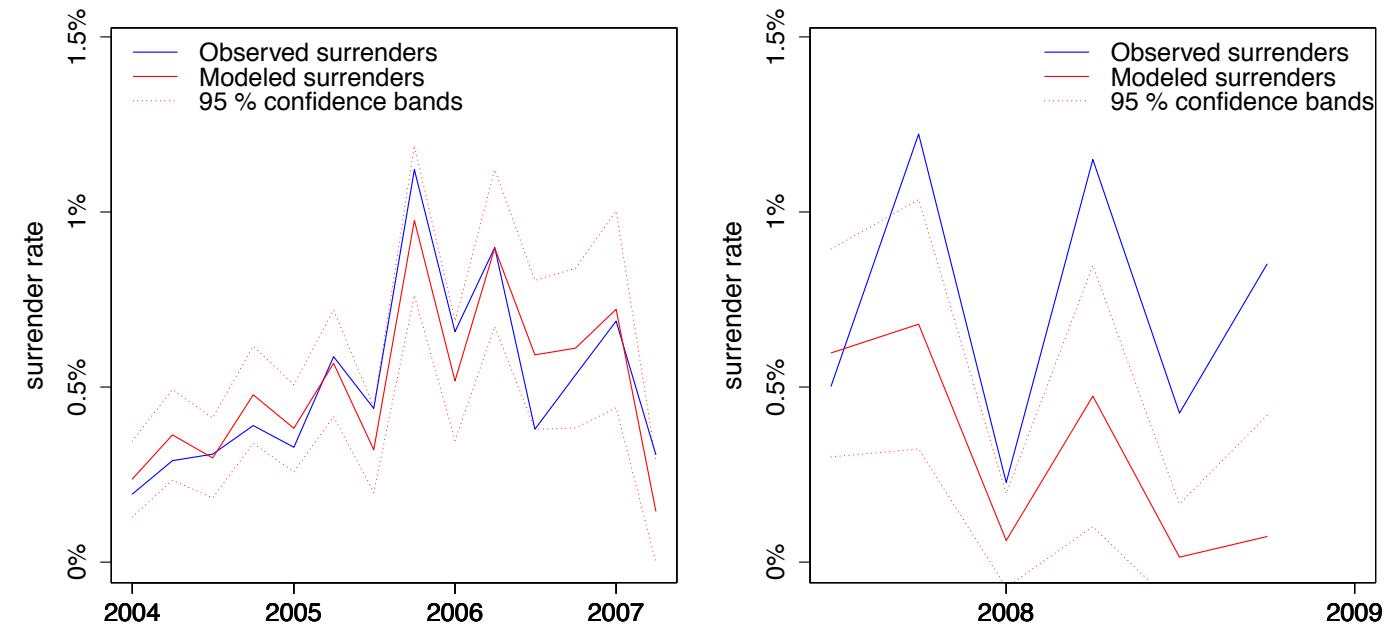

Figure 23. Quarterly predictions of the surrender rate by a logit model (left: learning sample, right: validation sample). Structured products. 

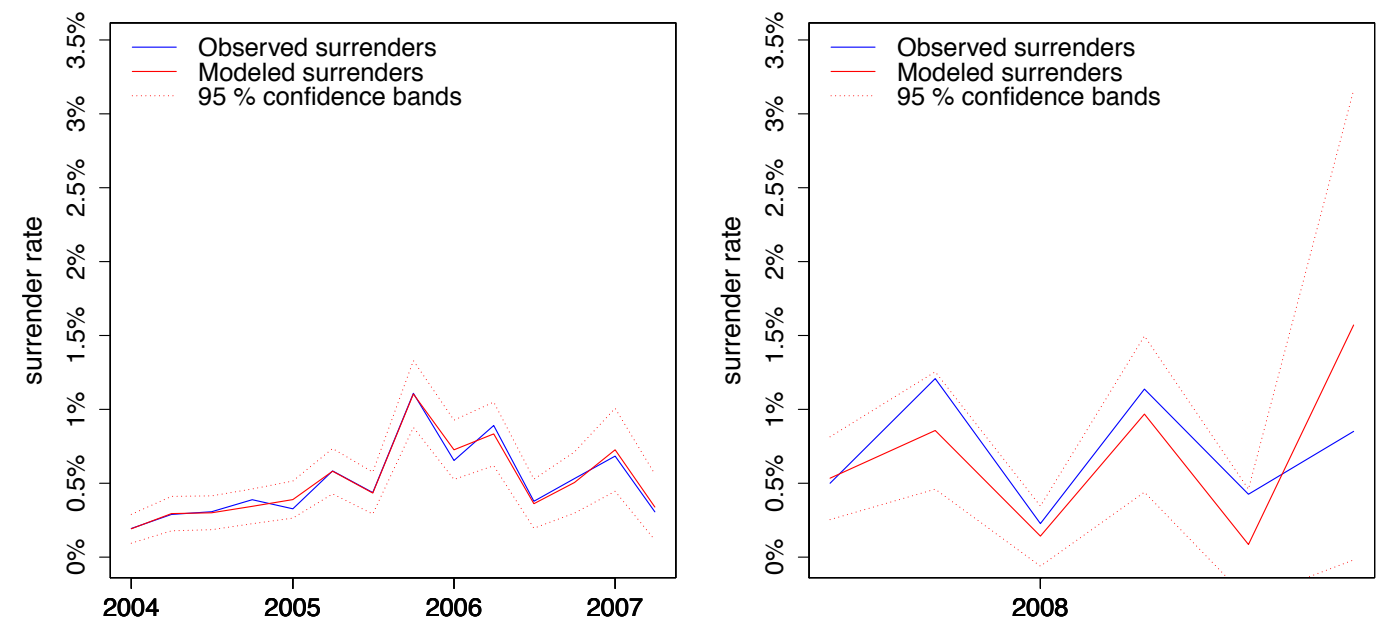

Figure 24. Quarterly predictions of the surrender rate by a logit mixture (left: learning sample, right: validation sample). Structured products.

the confidence interval of the logit predictions. With the mixture approach, we just need four components to catch the various effects impacting the surrender decisions. Let us guess that the correlation between policyholders' decisions is likely to increase faster on this type of contracts: this leads us to consider an exogenous covariate (10Y bond rate) in the weights of components. This way, the policyholders belonging to a given component are virtually allowed to change (representing a trade-off between rational and irrational behaviours); making the component weights rebalanced depending on the economic context. Notice also that we do not consider any structural effect in the component densities because the surrender behaviours were manifestly not affected by them.

Table 2 summarizes the main results for each product family. The standard deviation of the estimated regression coefficient determines its confidence level, denoted by $C f$ on a simplified scale. When $C f$ equals 1 , the fitting does not seem robust; $C f=2$ means that the estimation is satisfying and $C f=3$ corresponds to an excellent estimation. The global relevance of the model is assessed by statistical tests (Pearson and Wilcoxon), and confirmed by graphical outputs with the same scale as previously. \# is the number of components in the final selected mixture. The last column provides for additional information: the size of the learning and validation samples, the lookback period delta and the beginning date of the modelling. All these parameters were set equal to demonstrate the robustness of the methodology, whatever the family considered. 


\begin{tabular}{|c|c|c|c|c|c|c|c|c|c|}
\hline \multirow[t]{3}{*}{ Family } & \multirow{2}{*}{\multicolumn{2}{|c|}{$\begin{array}{l}\text { Covariates } \\
\text { in weights }\end{array}$}} & \multicolumn{4}{|c|}{ Covariates in components } & \multirow[t]{3}{*}{$\#$} & \multirow{3}{*}{$\begin{array}{l}\text { Global } \\
\text { quality }\end{array}$} & \multirow{3}{*}{$\begin{array}{l}\text { Other remarks: } \\
\text { learning sample size, } \\
\text { lookback period "delta" }\end{array}$} \\
\hline & & & fixed $\beta$ & & free $\beta$ & & & & \\
\hline & Name & $C f$ & Name & $C f$ & Name & $C f$ & & & \\
\hline Ahorro & intercept & 2 & $\begin{array}{l}\text { seasonality } \\
\text { duration } \\
\text { premium frequency } \\
\text { underwriting age } \\
\text { P-S option }\end{array}$ & $\begin{array}{l}3 \\
3 \\
3 \\
3 \\
3\end{array}$ & $\begin{array}{l}\text { intercept } \\
10 \mathrm{Y} \text { rate }\end{array}$ & $\begin{array}{l}3 \\
3\end{array}$ & 5 & 3 & $\begin{array}{l}\text { learning sample size: } 2 / 3 \\
\text { delta: } 1 \text { quarter } \\
\text { beginning date: } 1 / 1 / 2000\end{array}$ \\
\hline $\begin{array}{l}\text { Index } \\
\text { Link }\end{array}$ & intercept & 3 & $\begin{array}{l}\text { duration } \\
\text { underwriting age } \\
\text { gender }\end{array}$ & $\begin{array}{l}3 \\
2 \\
3\end{array}$ & $\begin{array}{l}\text { intercept } \\
\text { ibex } 35\end{array}$ & $\begin{array}{l}3 \\
2\end{array}$ & 2 & 3 & $\begin{array}{l}\text { learning sample size: } 2 / 3 \\
\text { delta: } 1 \text { quarter } \\
\text { beginning date: } 1 / 1 / 2000\end{array}$ \\
\hline Mixtos & intercept & 1 & $\begin{array}{l}\text { seasonality } \\
\text { duration } \\
\text { P-S option }\end{array}$ & $\begin{array}{l}3 \\
3 \\
3\end{array}$ & $\begin{array}{l}\text { intercept } \\
\text { risk premium } \\
10 \mathrm{Y} \text { rate }\end{array}$ & $\begin{array}{l}3 \\
3 \\
3\end{array}$ & 5 & 3 & $\begin{array}{l}\text { learning sample size: } 2 / 3 \\
\text { delta: } 1 \text { quarter } \\
\text { beginning date: } 1 / 1 / 2000\end{array}$ \\
\hline $\begin{array}{c}\text { Pure } \\
\text { Savings }\end{array}$ & intercept & 2 & $\begin{array}{l}\text { seasonality } \\
\text { duration } \\
\text { underwriting age }\end{array}$ & $\begin{array}{l}2 \\
3 \\
3\end{array}$ & $\begin{array}{l}\text { intercept } \\
\text { ibex } 35 \\
\text { 10Y rate }\end{array}$ & $\begin{array}{l}2 \\
3 \\
3\end{array}$ & 4 & 2 & $\begin{array}{l}\text { learning sample size: } 2 / 3 \\
\text { delta: } 1 \text { quarter } \\
\text { beginning date: } 1 / 1 / 2004\end{array}$ \\
\hline $\begin{array}{l}\text { Unit } \\
\text { Link }\end{array}$ & intercept & 2 & $\begin{array}{l}\text { seasonality } \\
\text { duration } \\
\text { risk premium }\end{array}$ & $\begin{array}{l}2 \\
3 \\
3\end{array}$ & $\begin{array}{l}\text { intercept } \\
\text { ibex } 35\end{array}$ & $\begin{array}{l}3 \\
3\end{array}$ & 5 & 3 & $\begin{array}{l}\text { learning sample size: } 2 / 3 \\
\text { delta: } 1 \text { quarter } \\
\text { beginning date: } 1 / 1 / 2000\end{array}$ \\
\hline $\begin{array}{l}\text { Universal } \\
\text { Savings }\end{array}$ & intercept & 3 & $\begin{array}{l}\text { seasonality } \\
\text { duration } \\
\text { underwriting age } \\
\text { distribution network }\end{array}$ & $\begin{array}{l}3 \\
3 \\
2 \\
3\end{array}$ & $\begin{array}{l}\text { intercept } \\
\text { wealth }\end{array}$ & $\begin{array}{l}3 \\
3\end{array}$ & 5 & 3 & $\begin{array}{l}\text { learning sample size: } 2 / 3 \\
\text { delta: } 1 \text { quarter } \\
\text { beginning date: } 1 / 1 / 2004\end{array}$ \\
\hline $\begin{array}{l}\text { Structured } \\
\text { products }\end{array}$ & $\begin{array}{l}\text { intercept } \\
10 \mathrm{Y} \text { rate }\end{array}$ & $\begin{array}{l}1 \\
2\end{array}$ & & & $\begin{array}{l}\text { intercept } \\
\text { Ibex } 35\end{array}$ & $\begin{array}{l}3 \\
3\end{array}$ & 4 & 3 & $\begin{array}{l}\text { learning sample size: } 2 / 3 \\
\text { delta: } 1 \text { quarter } \\
\text { beginning date: } 1 / 1 / 2004\end{array}$ \\
\hline
\end{tabular}

Selected models for each product family (\# : number of components in the mixture).

\section{Discussion and conclusion}

Interesting remarks follow from table 2. For instance some families could be grouped together if necessary, because the model structure and the selected risk factors are quite similar :

- contracts with a guaranteed return; we roughly model "Ahorro", "Mixtos", "Pure Savings" and "Universal Savings" products in the same way:

- structural effects encompass the seasonality, the duration, plus one or two endogenous variables depending on the family;

- temporary effects: dictated by the long-term (10Y) rate dynamics;

- correlation: potentially present if the policyholder's wealth is discriminant.

- contracts with a random return (Index-Link and Unit-Link):

- structural effects: duration and another risk factor depending on the fam- 
ily, no seasonality (or precious little);

- temporary effects: intense, dictated by financial markets (Ibex 35);

- correlation: potentially in case of a very adverse scenario.

- structured products: their complexity may explain this more "extreme" modelling :

- structural effects: no clear impact, thus no input in the regression mixture;

- temporary effects: intense, dictated by the financial markets performance;

- correlation: the size of the risky subpopulations (propensity to surrender) automatically goes up as the financial conditions are deteriorating.

We develop in this paper a new methodology to model the surrender behaviour. Empirical observations suggest to use regression models in order to integrate endogenous and exogenous risk factors. In particular, it is essential to take into account the heterogeneity and the correlation between behaviours. As a probabilistic alternative to previous works (where assumptions about policyholders' rationality and optimality are often required), mixture models enable to separate the different risk sources to reflect reality as much as we can. Structural effects are supposed to play the same role on the whole population, whereas cyclical trends have different impacts depending on the group of policyholders.

From a practical viewpoint, insurers could use such a model to improve their ALM by accurately predicting the future cash flows linked to surrenders (either on product families or on their flagship products). From our experience it is recommended to keep only a few risk factors, otherwise a too high dimensionality could affect the quality of predictions. Usually, some four covariates are considered: the seasonality, the contract duration, the economic context and the most discriminant endogenous variable. This standardized method seems to be efficient on various product families; provided that the analysis is performed with some intuition and horse sense. Of course, it does not pretend to be the solution whatever the products or the context. For example, hidden markov models are another attractive strategy that seems to be welladapted to model behaviours, but they are numerically time-consuming. The main advantage would be that the policyholders' behaviour would be "allowed to" change over the contract lifetime.

Acknowledgment The author would like to express deep gratitude to his Ph.D. supervisors, Stéphane Loisel and Véronique Maume-Deschamps, whose guidance and support were crucial for the successful completion of this project. He also thanks the referees and Ragnar Norberg for their useful comments. 


\section{References}

Bacinello, A. R. (2005), 'Endogenous model of surrender conditions in equitylinked life insurance', Insurance: Mathematics and Economics 37, 270-296.

Biard, R., Lefèvre, C. \& Loisel, S. (2008), 'Impact of correlation crises in risk theory: Asymptotics of finite-time ruin probabilities for heavy-tailed claim amounts when some independence and stationarity assumptions are relaxed', Insurance: Mathematics and Economics 43(3), 412 - 421.

Bluhm, W. F. (1982), 'Cumulative antiselection theory', Transactions of Society of actuaries $\mathbf{3 4}, 215-231$.

Breiman, L. (2001), 'Random forests', Machine Learning (45), 5-32.

Breiman, L., Friedman, J., Olshen, R. A. \& Stone, C. J. (1984), Classification and Regression Trees, Chapman and Hall.

Cox, D. (1972), 'Regression models and life tables (with discussion)', Journal of the Royal Statistical Society: Series B (34), 187-220.

Frühwirth-Schnatter, S. (2006), Finite Mixture and Markov Switching Models, Springer.

Hosmer, D. W. \& Lemeshow, S. (2000), Applied Logistic Regression, 2nd ed., Wiley.

Kagraoka, Y. (2005), Modeling insurance surrenders by the negative binomial model. Working Paper 2005.

Kim, C. (2005), 'Modeling surrender and lapse rates with economic variables', North American Actuarial Journal pp. 56-70.

Loisel, S. \& Milhaud, X. (2011), 'From deterministic to stochastic surrender risk models: Impact of correlation crises on economic capital', European Journal of Operational Research (214), 348-357.

McCullagh, P. \& Nelder, J. A. (1989), Generalized linear models, 2nd ed., Chapman and Hall.

McLachlan, G. \& Peel, D. (2000), Finite Mixture Models, Wiley Series In Porbability and Statistics.

Milhaud, X. (2011), Segmentation et modélisation des comportements de rachat en assurance-vie, Master's thesis, ISFA. Actuary memoir.

Milhaud, X., Maume-Deschamps, V. \& Loisel, S. (2011), 'Surrender triggers in life insurance: what main features affect the surrender behavior in a classical economic context?', Bulletin Francais d'Actuariat 22.

Schwarz, G. (1978), 'Estimating the dimension of a model', Annals of Statistics 6, $461-464$.

Siu, T. K. (2005), 'Fair valuation of participating policies with surrender options and regime switching', Insurance: Mathematics and Economics 37, 533-552.

Tsai, C., Kuo, W. \& Chen, W.-K. (2002), 'Early surrender and the distribution of policy reserves', Insurance: Mathematics and Economics 31, 429-445. 


\section{Appendix}

The following table summarizes the values of the BIC criterion for different logit mixtures (from two to five components). The lower this value is, the better the model fits the data (on the learning sample).

Table A.1

\begin{tabular}{|c|c|c|c|c|}
\hline Number of components & 2 & 3 & 4 & 5 \\
\hline BIC & 3067.8 & 2050.1 & 1820.1 & 1659.3 \\
\hline
\end{tabular}

BIC values of different candidate logit mixtures, endowment contracts.

Below are the parameters estimates (and their standard errors) of the selected logit mixture for endowment contracts.

\begin{tabular}{|c|c|c|c|c|c|}
\hline & Variables & Est. & Sd. err. & $\mathbf{z}$ & $P(>|z|)$ \\
\hline \multirow{4}{*}{ Weights } & Intercept & -0.54 & 0.23 & -2.32 & 0.020 \\
\hline & Intercept 1 & -0.66 & 0.24 & -2.74 & 0.005 \\
\hline & Intercept 2 & -1.85 & 0.39 & -4.66 & $3.134 \mathrm{e}-06$ \\
\hline & Intercept 3 & -0.55 & 0.23 & -2.36 & 0.018 \\
\hline \multirow{10}{*}{ Component 1} & end.month04 & 0.22 & 0.03 & 5.74 & $9.355 \mathrm{e}-09$ \\
\hline & end.month07 & 0.28 & 0.04 & 6.42 & $1.301 \mathrm{e}-10$ \\
\hline & end.month10 & 0.61 & 0.03 & 16.48 & $4.755 \mathrm{e}-61$ \\
\hline & duration.rangelow.duration & 0.24 & 0.07 & 3.28 & 0.001 \\
\hline & duration.rangemiddle.duration & 0.80 & 0.06 & 13.06 & $5.492 \mathrm{e}-39$ \\
\hline & PB.guaranteewithout_PB & -6.49 & 0.52 & -12.34 & $5.315 \mathrm{e}-35$ \\
\hline & Intercept & -5.52 & 0.06 & -88.45 & 0 \\
\hline & rate10Y & 2.49 & 0.50 & 4.89 & $9.747 \mathrm{e}-07$ \\
\hline & riskPrem.rangelow.risk.premium & -3.18 & 0.11 & -26.69 & $5.748 \mathrm{e}-157$ \\
\hline & riskPrem.rangemiddle.risk.premium & -0.80 & 0.06 & -12.94 & $2.569 \mathrm{e}-38$ \\
\hline \multirow{7}{*}{ Component 2} & end.month04 & 0.22 & 0.03 & 5.74 & $9.355 \mathrm{e}-09$ \\
\hline & end.month07 & 0.28 & 0.04 & 6.42 & $1.301 \mathrm{e}-10$ \\
\hline & end.month10 & 0.61 & 0.03 & 16.48 & $4.755 \mathrm{e}-61$ \\
\hline & duration.rangelow.duration & 0.24 & 0.07 & 3.28 & 0.001 \\
\hline & duration.rangemiddle.duration & 0.80 & 0.06 & 13.06 & $5.492 \mathrm{e}-39$ \\
\hline & PB.guaranteewithout_PB & -6.49 & 0.52 & -12.34 & $5.315 \mathrm{e}-35$ \\
\hline & Intercept & -5.96 & 0.07 & -81.56 & 0 \\
\hline
\end{tabular}


Table A.2 - concluded from previous page

\begin{tabular}{|c|c|c|c|c|c|}
\hline & Variables & Est. & Sd. err. & $\mathbf{z}$ & $P(>|z|)$ \\
\hline & rate $10 \mathrm{Y}$ & 4.32 & 0.40 & 10.64 & $1.852 \mathrm{e}-26$ \\
\hline & riskPrem.rangelow.risk.premium & 1.21 & 0.06 & 19.75 & $6.873 \mathrm{e}-87$ \\
\hline & riskPrem.rangemiddle.risk.premium & -2.34 & 0.20 & -11.68 & $1.490 \mathrm{e}-31$ \\
\hline \multirow{10}{*}{ Component 3} & end.month04 & 0.22 & 0.03 & 5.74 & $9.355 \mathrm{e}-09$ \\
\hline & end.month07 & 0.28 & 0.04 & 6.42 & $1.301 \mathrm{e}-10$ \\
\hline & end.month10 & 0.61 & 0.03 & 16.48 & $4.755 \mathrm{e}-61$ \\
\hline & duration.rangelow.duration & 0.24 & 0.07 & 3.28 & 0.001 \\
\hline & duration.rangemiddle.duration & 0.80 & 0.06 & 13.06 & $5.492 \mathrm{e}-39$ \\
\hline & PB.guaranteewithout_PB & -6.49 & 0.52 & -12.34 & $5.315 \mathrm{e}-35$ \\
\hline & Intercept & -8.28 & 0.19 & -42.83 & 0 \\
\hline & rate10Y & 1.60 & 0.55 & 2.86 & 0.004 \\
\hline & riskPrem.rangelow.risk.premium & 1.77 & 0.19 & 8.98 & $2.528 \mathrm{e}-19$ \\
\hline & riskPrem.rangemiddle.risk.premium & 2.55 & 0.18 & 13.79 & $2.615 \mathrm{e}-43$ \\
\hline \multirow{10}{*}{ Component 4} & end.month04 & 0.22 & 0.03 & 5.74 & $9.355 \mathrm{e}-09$ \\
\hline & end.month07 & 0.28 & 0.04 & 6.42 & $1.301 \mathrm{e}-10$ \\
\hline & end.month10 & 0.61 & 0.03 & 16.48 & $4.755 \mathrm{e}-61$ \\
\hline & duration.rangelow.duration & 0.24 & 0.07 & 3.28 & 0.001 \\
\hline & duration.rangemiddle.duration & 0.80 & 0.06 & 13.06 & $5.492 \mathrm{e}-39$ \\
\hline & PB.guaranteewithout_PB & -6.49 & 0.52 & -12.34 & $5.315 \mathrm{e}-35$ \\
\hline & Intercept & -5.15 & 0.08 & -60.86 & 0 \\
\hline & rate10Y & -5.23 & 0.76 & -6.86 & $6.556 \mathrm{e}-12$ \\
\hline & riskPrem.rangelow.risk.premium & 0.35 & 0.10 & 3.44 & 0.000 \\
\hline & riskPrem.rangemiddle.risk.premium & 0.29 & 0.07 & 4.07 & $4.666 \mathrm{e}-05$ \\
\hline \multirow{10}{*}{ Component 5} & end.month04 & 0.22 & 0.03 & 5.74 & $9.355 \mathrm{e}-09$ \\
\hline & end.month07 & 0.28 & 0.04 & 6.42 & $1.301 \mathrm{e}-10$ \\
\hline & end.month10 & 0.61 & 0.03 & 16.48 & $4.755 \mathrm{e}-61$ \\
\hline & duration.rangelow.duration & 0.24 & 0.07 & 3.28 & 0.001 \\
\hline & duration.rangemiddle.duration & 0.80 & 0.06 & 13.06 & $5.492 \mathrm{e}-39$ \\
\hline & PB.guaranteewithout_PB & -6.49 & 0.52 & -12.34 & $5.315 \mathrm{e}-35$ \\
\hline & Intercept & -6.58 & 0.11 & -59.48 & 0 \\
\hline & rate10Y & 3.54 & 0.47 & 7.41 & $1.242 \mathrm{e}-13$ \\
\hline & riskPrem.rangelow.risk.premium & 0.72 & 0.09 & 7.70 & $1.265 \mathrm{e}-14$ \\
\hline & riskPrem.rangemiddle.risk.premium & 1.36 & 0.08 & 15.79 & $3.132 \mathrm{e}-56$ \\
\hline
\end{tabular}

Table A.2. Parameters estimates of the selected logit mixture. 